\title{
Vibrational analysis and structural implications of H-bonding in isolated and aggregated 2-amino-1-propanol: a study by MI-IR and Raman spectroscopy and molecular orbital calculations is $^{2}$
}

\author{
R. Fausto ${ }^{\mathrm{a}, *}$, C. Cacela ${ }^{\mathrm{b}}$, M.L. Duarte ${ }^{\mathrm{b}}$ \\ ${ }^{a}$ Departamento de Química, Universidade de Coimbra, P-3049 Coimbra, Portugal \\ ${ }^{\mathrm{b}}$ Departamento de Química e Bioquímica,CECUL, Faculdade de Ciências, Universidade de Lisboa, 1749-016 Lisboa, Portugal
}

Received 13 September 1999; received in revised form 21 October 1999; accepted 21 October 1999

\begin{abstract}
Isolated 2-amino-1-propanol (2AP) was studied by matrix-isolation infrared spectroscopy (MI-IR) in $\mathrm{Ar}$ and $\mathrm{Kr}$ and ab initio 6-31G ${ }^{*}$ calculations undertaken at the HF-SCF and MP2 levels of theory. For the first time, five different conformational states of $2 \mathbf{A P}$ could be experimentally observed, which could be correlated with the most stable forms predicted by the calculations. The first and second lowest energy forms correspond to conformers which exhibit a considerably strong intramolecular $\mathrm{OH} \cdots \mathrm{N}$ hydrogen bond $\left(\mathrm{g}^{\prime} \mathrm{Gg}^{\prime}\right.$ and $\left.\mathrm{gG}^{\prime} \mathrm{g}\right)$, while the less abundant forms observed in the matrices $\left(\mathrm{gGg}^{\prime}, \mathrm{gGt}\right.$ and $\mathrm{g}^{\prime} \mathrm{G}^{\prime} \mathrm{g}$ ) are characterized by having a weak intramolecular $\mathrm{NH} \cdots \mathrm{O}$ or $\mathrm{OH} \cdots \mathrm{N}$ bond. These results were reinforced by infrared solution studies of the compound in tetrachloromethane and tetrachloroethylene. The experimental data obtained for the pure liquid, where $\mathrm{OH} \cdots \mathrm{N}$ intermolecular hydrogen bonding dominates, indicate that the preferred conformation of the monomeric unit within the aggregates is similar to conformer gGt. (C) 2000 Elsevier Science B.V. All rights reserved.
\end{abstract}

Keywords: 2-Amino-1-propanol; Intra and intermolecular hydrogen bonding; Infrared and Raman spectra; Matrix isolation; HF-SCF and MP2 6-31 $\mathrm{G}^{*}$ ab initio calculations

\section{Introduction}

Aminoalcohols have been proposed as potential vitrifying agents for long term cryopreservation of biological tissues and organs [1,2]. The vitrifying ability of these compounds, i.e. the property of avoiding ice formation upon lowering the temperature to sub-zero temperatures when they are added to water

\footnotetext{
Dedicated to Professor James R. Durig on the occasion of his 65 th birthday.

* Corresponding author. Tel.: +351-239-852080; fax: +351-239827703.

E-mail address: rfausto@gemini.ci.uc.pt (R. Fausto).
}

in a given proportion, has been suggested to be controlled, at least in part, by different types of inter and intramolecular hydrogen bonds in which aminoalcohols can be involved [1,2]. In fact, the simultaneous presence of the amino and hydroxyl groups in the same molecule, both able to act as a H-bond donor and acceptor, opens a wide range of possible hydrogen bond interactions, in particular when the groups are close to each other.

The main limiting factor to a detailed study of aminoalcohols, one that justifies the unavailability of extensive structural and spectroscopic data on such molecules, is its tendency to aggregate under normal experimental conditions, as well as their appreciable 
degree of hygroscopicity. Matrix-isolation vibrational spectroscopy thus appeared as a very convenient method to study their monomeric forms and the main intramolecular interactions that characterize these forms. Complemented with theoretical results obtained at a convenient level of approximation $\left(6-31 \mathrm{G}^{*} \mathrm{HF}\right.$ and MP2 ab initio SCF-MO calculations), the results obtained by matrix-isolation spectroscopy on the monomeric species could then be used as a basis to interpret the experimental data obtained in condensed phases and to evaluate the dominant intermolecular interactions that are operating under these conditions.

Very recently, we began a systematic study of aminoalcohols using this method. We started analyzing in detail the conformational isomerism in isolated and liquid 2-aminoethanol (2AE) [3] and, later on, we studied the more complex aminoalcohol 3-amino-1-propanol (3AP) [4]. These studies allowed us to establish that, for the isolated $\mathbf{2 A E}$ and $\mathbf{3 A P}$ molecules, $\mathrm{OH} \cdots \mathrm{N}$ and $\mathrm{NH} \cdots \mathrm{O}$ intramolecular hydrogen bonding may occur, the former being considerably stronger than the latter and being present in the most stable conformers $[3,4]$. On the contrary, in the liquid phase, the intramolecular $\mathrm{NH}$... O hydrogen bonding was found to play a prominent role in stabilizing the conformations assumed by the monomeric units within the aggregates. Under these conditions, the $\mathrm{OH} \cdots \mathrm{N}$ intermolecular hydrogen bonding becomes the prevalent interaction $[3,4]$. It is worth mentioning that, in agreement with the strong intramolecular $\mathrm{OH} \cdots \mathrm{N}$ hydrogen bond present in the conformational ground state of $\mathbf{3 A P}$, which reduces its tendency to aggregate, the spectroscopic data obtained for this molecule clearly shows that monomers assuming this conformation are also present in detectable amounts in the pure liquid [4]. In addition, the intramolecular $\mathrm{OH} \cdots \mathrm{N}$ hydrogen bonding in $\mathbf{2 A E}$ is considerably weaker than in $\mathbf{3 A P}$, and in accordance we did not observe any experimental evidence of the presence of monomeric species in the pure liquid.

In this paper, we present results obtained for 2amino-1-propanol (2AP), following a similar approach to that used in our previous studies on 2AE and 3AP [3,4]. 2AP differs structurally from 2AE by replacement of one of the $\mathrm{H}$ atoms of carbon-2 by an electron releasing methyl group. Besides imposing additional steric restrictions, the presence of the extra methyl group is expected to lead to an increase of the basicity of the amino group and, consequently, the $\mathrm{O}-\mathrm{H} \cdots \mathrm{N}$ hydrogen bonding in 2AP could be anticipated to be stronger than in 2AE. It is, however, considerably more difficult to predict the relative strength of this interaction in 2AP and in 3AP simply by using thumb-rules, since the increased conformational flexibility in $\mathbf{3 A P}$ shall certainly lead to a more favorable interaction geometry. This effect may overcome the absence of the methyl substituent in the carbon atom bearing the amine group. Thus, in the present study, we took this issue under consideration. In particular, the presence or not of monomeric forms of $\mathbf{2 A P}$ in the liquid phase (which, as mentioned above, is a good measure of the relative importance of the $\mathrm{OH} \cdots \mathrm{N}$ intramolecular interaction) is analyzed.

\section{Experimental}

2AP (D isomer) was obtained commercially spectroscopic grade (Aldrich, purity 99\%+) and was used without any additional purification. The sample was handled in a glove box to avoid moisture from air. To undertake the matrix-isolation infrared studies the sample was pre-mixed with $\operatorname{Ar}(99.999 \%$ purity) or $\mathrm{Kr}$ (99.998\%) under reduced pressure. The gas mixtures (matrix : solute $=1500$ ) thus formed were then sprayed onto the cold $\mathrm{KBr}$ window at $12 \mathrm{~K}$. The gas flux was controlled with two Swagelok valves (models BMG and BMRG), which make the connection to an APD cryogenics DMX closed cycle helium refrigeration system whose principal component is a DE-202 Displex expander. The refrigeration system is supported by an APD cryogenics Helium compressor (model HC-2D-1). For the conventional IR spectra a specially designed demountable transmission variable temperature cell with $\mathrm{KBr}$ windows, linked to a T48 (Red Lion Controls) temperature controller was used. The IR spectra were obtained using a Mattson (Infinity Series) or a Bomem (MB104) Fourier Transformer spectrometer equipped with a deuterated triglycine sulphide (DTGS) detector and $\mathrm{Ge} / \mathrm{KBr}$ or $\mathrm{Zn} / \mathrm{Se}$ optics. Data collection was performed with $1 \mathrm{~cm}^{-1}$ spectral resolution. Solution studies were undertaken at room temperature using $\mathrm{CCl}_{4}$ (Riedelde-Häen, spectroscopic grade) and $\mathrm{Cl}_{2} \mathrm{C}=\mathrm{CCl}_{2}$ 
(Merck, purity 99\%+) as solvents and covering a concentration range from $2.5 \times 10$ to $5.0 \times 10^{-1} \mathrm{M}$.

Raman spectrum was obtained using a Spex 1403 double monochromator spectrometer (focal length $0.85 \mathrm{~m}$, aperture $f / 7.8$ ) equipped with holographic gratings with 1800 groove $/ \mathrm{mm}$ (reference 18001SHD). The $514.5 \mathrm{~nm} \mathrm{Ar}^{+}$laser, adjusted to provide $220 \mathrm{~mW}$ power at the sample, was used as excitation radiation. Detection was effected using a thermoelectrically cooled Hamamatsu R928 photomultiplier. The spectrum was recorded using increments of $1 \mathrm{~cm}^{-1}$ and integration times of $1 \mathrm{~s}$.

Band intensities of matrix-isolation and Raman spectra were obtained from the area of the observed peaks, subjected to previous deconvolution by using the peak fitting module of ORIGIN 4.0 [5].

A simulation of the calculated $\mathrm{HF}$ 6-31G ${ }^{*}$ spectrum of isolated 3AP was performed by gaussian synthesis, from the ab initio frequencies and intensities, using the SYNSPEC program [6].

The ab initio molecular orbital calculations were performed using the $6-31 \mathrm{G}^{*}$ basis set [7] with the GAUSSIAN92/DFT program package [8] running on a DEC ALPHA 7000 computer. Molecular geometries were fully optimized by the force gradient method using Berny's algorithm [9] and the standard convergence criteria for the geometry optimization both at the Hartree-Fock and MP2 levels of theory. The HF $6-31 G^{*}$ ab initio calculated vibrational spectra were then used to help interpretation of the spectroscopic results, the calculated wavenumbers being scaled down in order to fit to the experimental values by using a single scale factor (0.89 [10]). Normal coordinates analysis was undertaken using the programs Transformer, Build-G and Vibrat [11] which are interfaced with GAUSSIAN92.

\section{Results and discussion}

2AP is characterized by three independent torsional angles which can give rise to conformational isomerism $(l p-\mathrm{N}-\mathrm{C} 2-\mathrm{C} 1, \mathrm{~N}-\mathrm{C}-\mathrm{C}-\mathrm{O}$ and $\mathrm{C}-\mathrm{C}-$ $\mathrm{O}-\mathrm{H} ; l p=$ lone pair). The different stable conformations are obtained by rotation around the $\mathrm{C}-\mathrm{N}, \mathrm{C} 1-$ $\mathrm{C} 2$ and $\mathrm{C}-\mathrm{O}$ bonds, and the values of the appropriate dihedral angles are, in all cases, expected to be close to $60,-60$ and $180^{\circ}$. This makes the number of total structures candidate to be a minimum in the potential energy surface of 2AP equals to 27. To name the conformers, we used three letters, the first referring to the configuration around the $\mathrm{C}-\mathrm{N}$ bond, the second and third to the configuration around the $\mathrm{C} 1-\mathrm{C} 2$ and $\mathrm{C}-\mathrm{O}$ bonds, respectively; the letters $\mathrm{g} / \mathrm{G}, \mathrm{g}^{\prime} / \mathrm{G}^{\prime}$ and $\mathrm{t} / \mathrm{T}$ indicate dihedral angles close to $60,-60$ and $180^{\circ}$, respectively. As $\mathrm{C} 2$ is a chyral atom, $\mathbf{2 A P}$ exists in two enantiomeric forms ( $D$ and $\mathrm{L}$ ), but these should have the same intramolecular interactions and give rise to identical vibrational spectra.

To the best of our knowledge, monomeric 2AP has only been studied previously by Ellingsen, Marstokk and Møllendal by microwave spectroscopy [12]. In that study, two conformers were observed for $\mathbf{2 A P}$, each with an intramolecular $\mathrm{OH} \cdots \mathrm{N}$ hydrogen bond. The most stable form has the methyl group approximately anti to the $\mathrm{C}-\mathrm{O}$ bond, while the second observed conformer has this group in a gauche position relatively to the $\mathrm{C}-\mathrm{O}$ bond. The $\mathrm{OCCN}$ angle was estimated to be $54 \pm 2^{\circ}$ in the conformational ground state and $61.5 \pm 2^{\circ}$ in the higher energy form $\left(\Delta G^{\circ}=\right.$ $2.43 \pm 0.71 \mathrm{~kJ} \mathrm{~mol}^{-1}$ [12]). Higher energy conformers were predicted to have at least energy $2 \mathrm{~kJ} \mathrm{~mol}^{-1}$ above the second more stable form [12]. Further, some relevant structural parameters (e.g. CCC angles and OCCN and OCCC dihedrals) and dipole moments for the two observed conformers, as well as the frequencies of three low frequency vibrational modes of the most stable conformer and one of the second rotamer were also obtained from the microwave data. However, complete structures have not been determined and no further vibrational information could be obtained.

\subsection{Molecular structures and energies}

In this study, the 27 structures having the appropriate combination of values of the $l p-\mathrm{N}-\mathrm{C} 2-\mathrm{C} 1, \mathrm{~N}-$ $\mathrm{C}-\mathrm{C}-\mathrm{O}$ and $\mathrm{C}-\mathrm{C}-\mathrm{O}-\mathrm{H}$ dihedral angles were given as input to the minimizing program. After minimization, all but two of these structures converged to the corresponding local minima in both the HF and MP2 potential energy surfaces of $\mathbf{2 A P}$. The two exceptions ( $\mathbf{g}^{\prime} \mathbf{G g}$ and $\mathbf{g G}^{\prime} \mathbf{g}^{\prime}$ initial conformations, where considerably strong steric interactions between the hydroxyl group and either the methyl or amino groups were expected to occur) converged to the most stable 
Table 1

Zero-point vibrational energy corrected relative energies $\left(\mathrm{kJ} \mathrm{mol}^{-1}\right)$ of the 25 different stable conformations of 2-amino-1-propanol, calculated at the MP2 and HF 6-31G ${ }^{*}$ levels of theory

\begin{tabular}{lrr}
\hline Conformer & $\Delta E$ & \\
\cline { 2 - 3 } & MP2 & HF \\
\hline $\mathbf{g}^{\prime} \mathbf{G g}^{\prime}$ & 0.00 & 0.00 \\
$\mathbf{g G} \mathbf{g}$ & 0.92 & 1.62 \\
$\mathbf{g G g}$ & 9.29 & 6.97 \\
$\mathbf{g G t}$ & 9.45 & 5.76 \\
$\mathbf{g}^{\prime} \mathbf{G}^{\prime} \mathbf{g}$ & 9.64 & 8.45 \\
$\mathbf{g G g}$ & 10.07 & 7.61 \\
$\mathbf{t G g}$ & 10.08 & 8.31 \\
$\mathbf{t G t}$ & 10.75 & 7.37 \\
$\mathbf{g}^{\prime} \mathbf{G}^{\prime} \mathbf{t}$ & 11.59 & 8.85 \\
$\mathbf{t G} \mathbf{g}^{\prime}$ & 12.10 & 10.77 \\
$\mathbf{t G} \mathbf{t}$ & 12.62 & 9.65 \\
$\mathbf{g}^{\prime} \mathbf{G}^{\prime} \mathbf{g}^{\prime}$ & 13.18 & 11.79 \\
$\mathbf{t G g}$ & 14.83 & 12.11 \\
$\mathbf{g}^{\prime} \mathbf{T g}$ & 14.92 & 11.01 \\
$\mathbf{t T g}$ & 15.03 & 12.10 \\
$\mathbf{g T g}^{\prime}$ & 15.30 & 10.90 \\
$\mathbf{g T t}^{\prime}$ & 15.36 & 9.79 \\
$\mathbf{g}^{\prime} \mathbf{T t}$ & 15.55 & 10.59 \\
$\mathbf{t G} \mathbf{g}$ & 15.85 & 14.03 \\
$\mathbf{g} \mathbf{g} \mathbf{t}$ & 15.96 & 11.36 \\
$\mathbf{t T g}$ & 16.06 & 13.01 \\
$\mathbf{t T t}$ & 16.26 & 11.84 \\
$\mathbf{g}^{\prime} \mathbf{T g}$ & 17.39 & 13.26 \\
$\mathbf{g G}^{\prime} \mathbf{t}$ & 26.25 & 21.72 \\
$\mathbf{g}^{\prime} \mathbf{G t}$ & 27.46 & 22.37 \\
\hline & & \\
\hline
\end{tabular}

$\mathbf{g}^{\prime} \mathbf{G} \mathbf{g}^{\prime}$ and $\mathbf{g G} \mathbf{g}$ forms, from which they may easily be obtained by internal rotation around the $\mathrm{C}-\mathrm{C}-\mathrm{O}-\mathrm{H}$ axis. The relative energies of the 25 calculated minima are shown in Table 1. The five most stable conformers are depicted in Fig. 1 and their calculated geometries, relative energies and predicted populations at room temperature (assuming a Boltzmann distribution) are presented and compared with the available experimental data in Table $2{ }^{1}$

Considering the sum of Van der Waals radii of $(\mathrm{H}+\mathrm{N})=270 \mathrm{pm}$ and $(\mathrm{H}+\mathrm{O})=260 \mathrm{pm} \quad[13]$, conformers $\mathbf{g}^{\prime} \mathbf{G g}^{\prime}, \mathbf{g G} \mathbf{G}^{\prime} \mathbf{g}, \mathbf{g G g} \mathbf{g}^{\prime}$ and $\mathbf{g}^{\prime} \mathbf{G}^{\prime} \mathbf{g}$, with $\mathrm{d}(\mathrm{OH} . . \mathrm{N})<270 \mathrm{pm}$, and conformer gGt, with $\mathrm{d}(\mathrm{NH} . . \mathrm{O})<260 \mathrm{pm}$, are considered to be stabilized by an $\mathrm{OH} \cdots \mathrm{N}$ or $\mathrm{NH} \cdots \mathrm{O}$ intramolecular hydrogen

\footnotetext{
${ }^{1}$ Complete structural data for the higher energy local minima may be obtained from the corresponding author upon request.
}
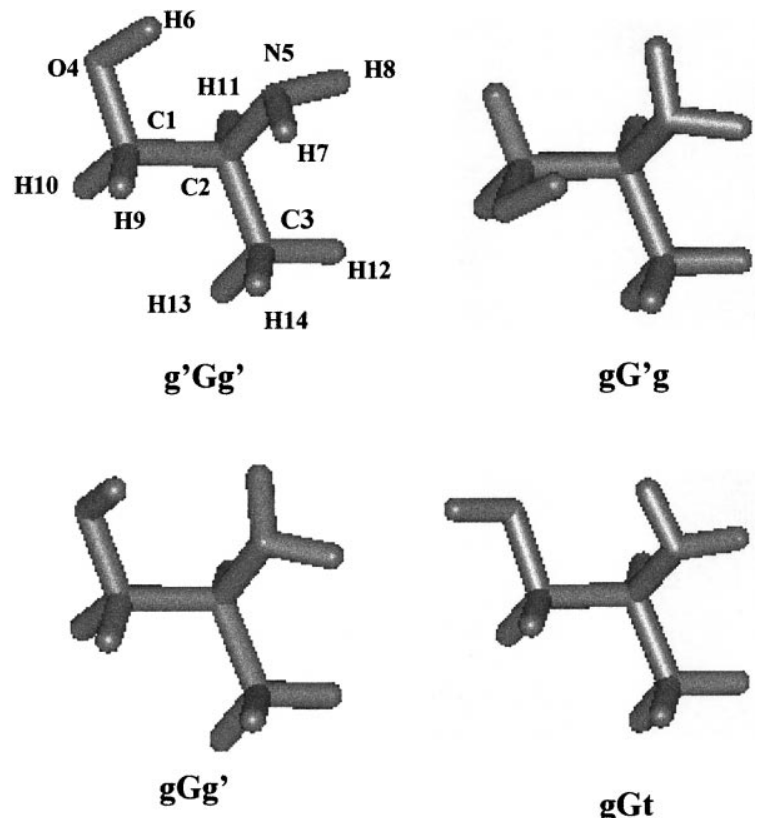

gG'g

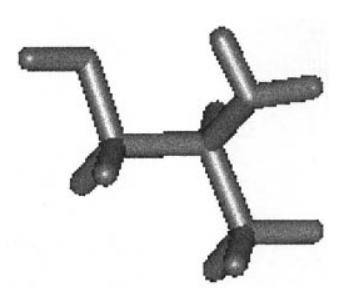

gGt

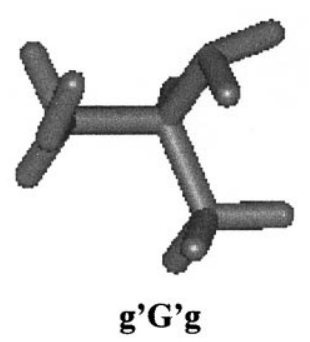

Fig. 1. The most stable conformers of 2-amino-1-propanol and numbering atom scheme.

bond, respectively. In the first and second more stable conformers $\left(\mathbf{g}^{\prime} \mathbf{G g}^{\prime}, \mathbf{g G} \mathbf{G}^{\prime} \mathbf{g}\right)$, which have nearly the same energy $\left(\Delta E_{\mathbf{g G}^{\prime} \mathbf{g}-\mathbf{g}^{\prime} \mathbf{G g}^{\prime}}=0.92 \mathrm{~kJ} \mathrm{~mol}^{-1}\right)$, the $\mathrm{d}(\mathrm{OH} \cdots \mathrm{N})$ distance is much smaller than the sum of the Van der Waals radii of $(\mathrm{H}+\mathrm{N})$ (see Table 2) and the hydrogen bonding is strong. This is certainly the most important intramolecular stabilizing factor acting in these two conformers and justify the fact that they are by far the most stable forms of $\mathbf{2 A P}$. On the contrary, in the forms $\mathbf{g G g}^{\prime}$ and $\mathbf{g}^{\prime} \mathbf{G}^{\prime} \mathbf{g}$, $\mathrm{d}(\mathrm{OH} \cdots \mathrm{N})$ is closer to the sum of the Van der Waals radii of $(\mathrm{H}+\mathrm{N})$. As a result, in these forms the hydrogen bonds are much weaker and the relative energies are considerably higher than in the two lowest energy conformers (the MP2 predicted excess 
Table 2

Experimental and MP2 6-31G* calculated relevant structural and energetic data for the most stable forms of 2-amino-1-propanol (relative energies to the most stable conformer, $\Delta E$, in $\mathrm{kJ} \mathrm{mol}^{-1}$; predicted populations, $p(\%)$, at room temperature, were calculated assuming a Boltzmann distribution (the total pupulation of the remaining conformers is predicted as $p<15.3 \%$ and $p<5.1 \%$ at the HF and MP2 levels of theory, respecitvely); bond lengths and distances in pm; angles in degrees; total dipole moments, $\mu$, in Debye $\left(1 \mathrm{D}=3.33564 \times 10^{-30} \mathrm{~cm}\right)$

\begin{tabular}{|c|c|c|c|c|c|c|c|}
\hline & \multicolumn{2}{|l|}{$\mathbf{g}^{\prime} \mathbf{G} \mathbf{g}^{\prime}$} & \multicolumn{2}{|l|}{$\mathbf{g G}^{\prime} \mathbf{g}$} & \multirow{2}{*}{$\frac{\mathbf{g G g}^{\prime}}{\mathrm{MP} 2}$} & \multirow{2}{*}{$\begin{array}{l}\mathbf{g G t} \\
\mathrm{MP} 2\end{array}$} & \multirow{2}{*}{$\begin{array}{l}\mathbf{g}^{\prime} \mathbf{G}^{\prime} \mathbf{g} \\
\mathrm{MP} 2\end{array}$} \\
\hline & Exp. $^{a}$ & MP2 & Exp. $^{a}$ & MP2 & & & \\
\hline$\Delta E$ & - & - & $2.43 \pm 0.71$ & 0.92 & 9.29 & 9.45 & 9.64 \\
\hline$\Delta E^{\mathrm{b}}$ & - & - & & 1.62 & 6.97 & 5.76 & 8.45 \\
\hline$p$ & & 54.0 & & 37.3 & 1.3 & 1.2 & 1.1 \\
\hline$p^{\mathrm{b}}$ & & 49.5 & & 25.8 & 3.0 & 4.9 & 1.6 \\
\hline \multicolumn{8}{|c|}{ Bond length } \\
\hline $\mathrm{C} 1 \mathrm{C} 2$ & & 152.6 & & 152.8 & 152.4 & 151.5 & 152.7 \\
\hline $\mathrm{C} 2 \mathrm{C} 3$ & & 152.4 & & 152.1 & 152.1 & 152.2 & 152.6 \\
\hline $\mathrm{CO}$ & & 141.7 & & 141.9 & 142.6 & 143.2 & 142.7 \\
\hline $\mathrm{CN}$ & & 147.3 & & 147.4 & 147.3 & 146.4 & 147.6 \\
\hline $\mathrm{OH}$ & & 97.9 & & 97.9 & 97.4 & 97.1 & 97.4 \\
\hline NH7 & & 102.1 & & 101.9 & 101.9 & 101.9 & 102.0 \\
\hline NH8 & & 101.9 & & 102.0 & 101.9 & 101.9 & 101.9 \\
\hline $\mathrm{CH} 9$ & & 110.5 & & 109.4 & 110.0 & 109.8 & 109.4 \\
\hline $\mathrm{CH} 10$ & & 109.4 & & 110.3 & 109.4 & 110.0 & 109.8 \\
\hline $\mathrm{CH} 11$ & & 109.6 & & 110.3 & 110.2 & 110.4 & 109.8 \\
\hline $\mathrm{CH} 12$ & & 109.4 & & 109.5 & 109.5 & 109.4 & 109.4 \\
\hline $\mathrm{CH} 13$ & & 109.5 & & 109.3 & 109.4 & 109.4 & 109.5 \\
\hline $\mathrm{CH} 14$ & & 109.6 & & 109.1 & 109.4 & 109.3 & 109.4 \\
\hline \multicolumn{8}{|l|}{ Angles } \\
\hline $\mathrm{CCC}$ & $112.4 \pm 1.0$ & 112.4 & $112.4 \pm 1.0$ & 111.5 & 110.8 & 111.0 & 111.8 \\
\hline $\mathrm{CCO}$ & & 110.6 & & 110.6 & 111.5 & 107.0 & 110.7 \\
\hline $\mathrm{CCN}$ & & 106.2 & & 106.0 & 106.9 & 107.5 & 106.6 \\
\hline $\mathrm{COH}$ & & 103.2 & & 103.3 & 104.6 & 107.8 & 104.4 \\
\hline CNH7 & & 109.2 & & 110.3 & 109.8 & 109.5 & 108.2 \\
\hline CNH8 & & 110.4 & & 110.0 & 108.7 & 107.9 & 109.8 \\
\hline $\mathrm{CCH} 9$ & & 108.8 & & 110.8 & 108.8 & 108.6 & 111.2 \\
\hline $\mathrm{CCH} 10$ & & 110.8 & & 109.2 & 110.7 & 110.1 & 109.3 \\
\hline $\mathrm{CCH} 11$ & & 107.1 & & 108.5 & 108.0 & 106.7 & 107.9 \\
\hline $\mathrm{CCH} 12$ & & 110.9 & & 111.0 & 111.2 & 110.5 & 111.0 \\
\hline $\mathrm{CCH} 13$ & & 111.3 & & 110.5 & 111.0 & 111.3 & 111.4 \\
\hline CCH14 & & 110.4 & & 109.7 & 109.8 & 109.8 & 109.4 \\
\hline \multicolumn{8}{|l|}{ Dihedrals } \\
\hline $\mathrm{CCCO}$ & $180.0 \pm 2.0$ & 179.9 & $-60.0 \pm 1.0$ & 62.9 & 169.4 & 182.7 & 73.0 \\
\hline OCCN & $-54.0 \pm 2.0$ & 53.9 & $61.5 \pm 2.0$ & -55.6 & 49.6 & 63.0 & -51.4 \\
\hline $\mathrm{CCOH}$ & & -39.5 & & 41.1 & -69.3 & 192.1 & 68.1 \\
\hline $\mathrm{CCNH} 7$ & & 78.3 & & 167.9 & 161.7 & 188.5 & 88.3 \\
\hline CCNH8 & & 194.9 & & -75.0 & -83.1 & -55.7 & 203.1 \\
\hline NCCH9 & & -68.7 & & 185.3 & -72.9 & -57.1 & 190.4 \\
\hline NCCH10 & & 173.1 & & 66.9 & 167.9 & 183.7 & 70.6 \\
\hline OCCH11 & & -59.4 & & 183.1 & -71.1 & -58.6 & 193.5 \\
\hline $\mathrm{CCCH} 12$ & & 179.4 & & 182.4 & 176.0 & 180.4 & 183.7 \\
\hline $\mathrm{CCCH} 13$ & & 59.1 & & 62.7 & 56.0 & 60.6 & 63.1 \\
\hline $\mathrm{CCCH} 14$ & & -60.8 & & -57.0 & -64.1 & -60.5 & -56.3 \\
\hline $\mathrm{COH} \cdots \mathrm{N}$ & & 14.1 & & 15.0 & 44.3 & & -42.8 \\
\hline $\mathrm{CNH} \cdots \mathrm{O}$ & & & & & & 25.9 & \\
\hline
\end{tabular}


Table 2 (continued)

\begin{tabular}{|c|c|c|c|c|c|c|c|}
\hline & \multicolumn{2}{|l|}{$\mathbf{g}^{\prime} \mathbf{G} \mathbf{g}^{\prime}$} & \multicolumn{2}{|l|}{$\mathbf{g G}^{\prime} \mathbf{g}$} & \multirow{2}{*}{$\frac{\mathbf{g G g}^{\prime}}{\mathrm{MP} 2}$} & \multirow{2}{*}{$\begin{array}{l}\mathbf{g G t} \\
\mathrm{MP} 2\end{array}$} & \multirow{2}{*}{$\begin{array}{l}\mathbf{g}^{\prime} \mathbf{G}^{\prime} \mathbf{g} \\
\mathrm{MP} 2\end{array}$} \\
\hline & Exp. ${ }^{a}$ & MP2 & Exp. ${ }^{a}$ & MP2 & & & \\
\hline $\mathrm{d}(\mathrm{OH} \cdots \mathrm{N})$ & 211 & 213.3 & 223 & 216.1 & 239.0 & 356.9 & 236.3 \\
\hline $\mathrm{d}(\mathrm{NH} \cdots \mathrm{O})^{\mathrm{c}}$ & & 325.1 & & 323.7 & 261.8 & 234.6 & 267.3 \\
\hline$\mu^{\prime}$ & $3.13 \pm 0.05$ & 3.58 & $2.88 \pm 0.07$ & 3.40 & 2.25 & 1.11 & 2.31 \\
\hline$\mu^{\mathrm{b}}$ & & 3.28 & & 3.13 & 1.84 & 1.07 & 1.95 \\
\hline
\end{tabular}

energy to the conformational ground state is slightly larger than $9 \mathrm{~kJ} \mathrm{~mol}^{-1}$ ).

Amongst all the 25 stable conformations of 2AP, $\mathbf{g}^{\prime} \mathbf{G} \mathbf{g}^{\prime}, \mathbf{g G} \mathbf{G}^{\prime} \mathbf{g}, \mathbf{g G g} \mathbf{g}^{\prime}$ and $\mathbf{g}^{\prime} \mathbf{G}^{\prime} \mathbf{g}$ are the only ones exhibiting $\mathrm{OH} \cdots \mathrm{N}$ intramolecular hydrogen bonds. The fact that these four conformers are the first, second, third and fifth most stable strongly stresses the importance of this interaction. By looking at the spatial positions occupied by the different groups in these conformers (see Fig. 1), it can also be easily realized that the forms $\mathbf{g} \mathbf{G} \mathbf{g}^{\prime}$ and $\mathbf{g}^{\prime} \mathbf{G}^{\prime} \mathbf{g}$ (with the highest energy) are, respectively, related to the lowest energy forms, $\mathbf{g}^{\prime} \mathbf{G g}$ ' and $\mathbf{g G} \mathbf{g}^{\prime} \mathbf{g}$. Like $\mathbf{g G g} \mathbf{g}^{\prime}$ relatively to $\mathbf{g}^{\prime} \mathbf{G} \mathbf{g}^{\prime}$, $\mathbf{g}^{\prime} \mathbf{G}^{\prime} \mathbf{g}$ differs from $\mathbf{g} \mathbf{G}^{\prime} \mathbf{g}$ as far as the conformation assumed by the amino group is concerned. In fact, in the two lowest energy forms, the orientation of the hydroxyl hydrogen atom towards the lone electron pair of the nitrogen atom is adequate for a strong $\mathrm{H}$ bonding interaction (MP2 calculated $\mathrm{C}-\mathrm{O}-\mathrm{H} \cdots \mathrm{N}$ dihedral angles in $\mathbf{g}^{\prime} \mathbf{G} \mathbf{g}^{\prime}$ and $\mathbf{g} \mathbf{G}^{\prime} \mathbf{g}$ are 14.1 and $15.0^{\circ}$, respectively), while in the higher energy forms the relative orientation of the $\mathrm{OH}$ and $\mathrm{N}$ groups are far from being optimal (MP2 calculated $\mathrm{C}-\mathrm{O}-$ $\mathrm{H} \cdots \mathrm{N}$ dihedral angles in $\mathbf{g} \mathbf{G g}^{\prime}$ and $\mathbf{g}^{\prime} \mathbf{G}^{\prime} \mathbf{g}$ are 44.3 and $-42.8^{\circ}$, respectively).

Using the criteria based on the Van der Waals radii, described above, there are several stable conformations of 2AP predicted by the calculations to have an $\mathrm{NH} \cdots \mathrm{O}$ intramolecular hydrogen bond. As predicted by the MP2 calculations, these correspond to the fourth more stable conformer (gGt) and to the sixth to the twelfth conformers in the energy scale (see Table 1). Despite the $\mathrm{NH} \cdots \mathrm{O}$ hydrogen bond being the main responsible factor accounting for the stabilization of these 8 conformers of $\mathbf{2 A P}$ (they immediately follow in energy the conformers which have an $\mathrm{OH} \cdots \mathrm{N}$ hydrogen bond), it is, however, clear from the calculated $\mathrm{d}(\mathrm{NH} \cdots \mathrm{O})$ distances in these conformers, as well as from their relative energies that this interaction is, in all cases, considerably weak. As already mentioned, among the five most stable conformers only the gGt has this kind of interaction. In accordance to our interpretation, this was found to be the conformer where $\mathrm{d}(\mathrm{NH} \cdots \mathrm{O})$ attains its minimal value (i.e. where the $\mathrm{NH} \cdots \mathrm{O}$ hydrogen bond is stronger).

Looking now at the most important repulsive (destabilizing) intramolecular interactions present in the whole set of conformers of $\mathbf{2 A P}$, the following conclusions may be drawn:

(i) The energy of the two highest energy conformers ( $\mathbf{g G} \mathbf{G}^{\prime} \mathbf{t}$ and $\left.\mathbf{g}^{\prime} \mathbf{G t}\right)$ is mainly determined by the presence of the strongly repulsive interaction between the lone electron pairs of the oxygen and nitrogen atoms. This is by far the strongest repulsive interaction that can operate in the studied molecule.

(ii) The $\mathrm{OH} \cdots \mathrm{H}_{3} \mathrm{C}$ repulsion was found to be operating in the high energy forms $\mathbf{g T g}, \mathbf{g}^{\prime} \mathbf{T g}$ and $\mathbf{t T g}$ (all of them with an energy $16 \mathrm{~kJ} \mathrm{~mol}^{-1}$ above that of the conformational ground state), while the less important $\mathrm{OH} \cdots \mathrm{HC}$ interaction is the main repulsive interaction acting in conformers $\mathbf{g}^{\prime} \mathbf{T} \mathbf{g}^{\prime}, \mathbf{t} \mathbf{T} \mathbf{g}^{\prime}$ and $\mathbf{g} \mathbf{T g} \mathbf{g}^{\prime}$, which have an energy ca. $15 \mathrm{~kJ} \mathrm{~mol}^{-1}$ above than the lowest energy form.

(iii) Finally, in conformers $\mathbf{t G} \mathbf{g}^{\prime}$ and $\mathbf{t} \mathbf{G}^{\prime} \mathbf{g}$, that have the same configurations of the $\mathrm{N}-\mathrm{C}-\mathrm{C}-\mathrm{O}$ and $\mathrm{C}-$ $\mathrm{C}-\mathrm{O}-\mathrm{H}$ axes, like the first and third or the second and fifth most stable conformers, respectively, but 
different configuration of the $l p-\mathrm{N}-\mathrm{C} 2-\mathrm{C} 1$ axis, a repulsion occurs between the hydroxylic hydrogen atom and one of the hydrogen atoms of the amino group. This $\mathrm{OH} \cdots \mathrm{HN}$ repulsive interaction is the main factor contributing to the relatively high energy of these conformers.

As a summary, it can be stated that the conformational preferences exhibited by $\mathbf{2 A P}$ strongly depend on the intramolecular hydrogen bonding. Both $\mathrm{OH} \cdots \mathrm{N}$ and $\mathrm{NH} \cdots \mathrm{O}$ types of $\mathrm{H}$-bonds are important stabilizing factors, with the former assuming the most relevant role and being present in four of the five most stable conformers. Further, only the conformer with the strongest $\mathrm{NH} \cdots \mathrm{O}$ intramolecular hydrogen bonding has a relative energy that places it within the first five conformers in the energy scale. The strongest repulsive intramolecular interaction, which can operate in 2AP, is the one between the lone electron pairs of the oxygen and nitrogen atoms. Other relevant destabilizing intramolecular interactions found to occur in some conformers are the $\mathrm{OH} \cdots \mathrm{H}_{3} \mathrm{C}$, $\mathrm{OH} \cdots \mathrm{HC}$ and $\mathrm{OH} \cdots \mathrm{HN}$ repulsions, the first one being the most energetically relevant.

It is also interesting to compare the results obtained at the two levels of theory used. With the notable exception of the second most stable conformer, $\mathbf{g G}^{\prime} \mathbf{g}$, all energies relative to the most stable form are predicted to be larger by the MP2 than by the HF calculations. This result means essentially that the higher level MP2 calculations lead to an additional stabilization of the two most stable conformers. As the most important stabilizing factor in these two forms is the presence of a considerably strong intramolecular hydrogen bond, this result clearly shows the best performance of the MP2 method to rationalize these interactions. Indeed, this is in accordance to previous studies on molecules where intramolecular hydrogen bonding is important [14,15].

The dependence of geometrical parameters (bond lengths and angles) with conformation is also essentially determined by the type and relative importance of the different intramolecular interactions occurring in the various conformers. The MP2 calculated geometries show the usual differences when compared with the HF predictions: bond lengths are systematically longer and angles systematically smaller, a tendency that has been found to improve the general agreement between the theoretical and experimental data [16-18]. However, calculated changes of those parameters with conformation follow the same pattern as predicted by the two methods, though it is also clear from the structural results that the MP2 wavefunction accounts much better for the hydrogen bonding. For instance, the hydrogen bonding distances $\mathrm{d}\left(\mathrm{OH} \cdots \mathrm{N}\right.$ ) (in $\mathbf{g}^{\prime} \mathbf{G g}^{\prime}$, $\mathbf{g G}^{\prime} \mathbf{g}, \mathbf{g G g} \mathbf{g}^{\prime}$ and $\mathbf{g}^{\prime} \mathbf{G}^{\prime} \mathbf{g}$ ) and $\mathrm{d}(\mathrm{NH} \cdots \mathrm{O})$ (e.g. in $\mathbf{g G t}$ ) are considerably shorter at the MP2 level, while the $\mathrm{O}-\mathrm{C}-\mathrm{C}-\mathrm{N}$ and $\mathrm{C}-\mathrm{C}-\mathrm{O}-\mathrm{H}$ dihedral angles become smaller in these conformers having an $\mathrm{OH} \cdots \mathrm{N}$ hydrogen bond, in order to achieve a more favorable geometry for the establishment of the H-bond.

From the structural data presented in Table 2 it is possible to extract the following main conclusions:

(i) The $\mathrm{C}-\mathrm{O}$ bond length becomes shorter (i.e. the bond becomes stronger) when the $\mathrm{OH} \cdots \mathrm{N}$ intramolecular hydrogen bond becomes stronger. So, among the five conformers of 2AP considered now, this bond attains its minimum value in the most stable conformer $\mathbf{g}^{\prime} \mathbf{G g}^{\prime}$ and reaches its maximum value in form gGt (where the $\mathrm{OH} \cdots \mathrm{N}$ hydrogen bond does not exist). As expected, the opposite trend occurs for the change of the $\mathrm{O}-\mathrm{H}$ bond length with conformation, which increases with the strength of the hydrogen bond.

(ii) Relatively to the strength of the $\mathrm{NH} \cdots \mathrm{O}$ hydrogen bond, the $\mathrm{C}-\mathrm{N}$ bond length shows a similar behavior to the one exhibited by $\mathrm{C}-\mathrm{O}$ relatively to the strength of the $\mathrm{OH} \cdots \mathrm{N}$ hydrogen bonding. Thus, the $\mathrm{C}-\mathrm{N}$ bond is slightly shorter in conformer gGt $(146.4 \mathrm{pm})$ than in the conformers where no $\mathrm{NH} \cdots \mathrm{O}$ hydrogen bonding occurs (ca. $147.6 \mathrm{pm}$ ). In addition, the $\mathrm{N}-\mathrm{H}$ bond length does not appear to be strongly affected by $\mathrm{H}$ bonding, while it becomes shorter when the position of the hydrogen atom is trans with respect to the molecular skeleton. This result follows the general trend previously observed in other primary amines [19,20].

(iii) Among the five conformers of $\mathbf{2 A P}$ considered now, the gGt has the shortest $\mathrm{C} 1-\mathrm{C} 2$ bond length. This may be attributed to the fact that this is the only conformer where the hydroxyl group is in a trans position [21];

(iv) The valence angles are generally similar in all 
Table 3

MP2/6-31G* calculated Mülliken atomic charges (units of electron; $1 e^{-}=-1.6 \times 10^{-19} \mathrm{C}$ ) for the most stable forms of 2-amino-1propanol

\begin{tabular}{lrrrrr}
\hline & $\mathbf{g}^{\prime} \mathbf{G g}^{\prime}$ & \multicolumn{1}{c}{$\mathbf{g G} \mathbf{G}^{\prime} \mathbf{g}$} & \multicolumn{1}{c}{$\mathbf{g G g ^ { \prime }}$} & \multicolumn{1}{c}{$\mathbf{g G t}$} & \multicolumn{1}{c}{$\mathbf{g}^{\prime} \mathbf{G}^{\prime} \mathbf{g}$} \\
\hline C1 & 0.051 & 0.033 & 0.033 & 0.017 & 0.020 \\
C2 & -0.028 & -0.024 & 0.006 & 0.006 & -0.001 \\
C3 & -0.490 & -0.481 & -0.504 & -0.481 & -0.494 \\
O4 & -0.766 & -0.762 & -0.758 & -0.759 & -0.757 \\
N5 & -0.870 & -0.874 & -0.870 & -0.848 & -0.866 \\
H6 & 0.469 & 0.467 & 0.448 & 0.441 & 0.450 \\
H7 & 0.335 & 0.347 & 0.340 & 0.328 & 0.337 \\
H8 & 0.347 & 0.341 & 0.342 & 0.359 & 0.341 \\
H9 & 0.124 & 0.162 & 0.145 & 0.155 & 0.162 \\
H10 & 0.161 & 0.134 & 0.162 & 0.143 & 0.153 \\
H11 & 0.179 & 0.147 & 0.154 & 0.151 & 0.160 \\
H12 & 0.163 & 0.151 & 0.161 & 0.160 & 0.155 \\
H13 & 0.169 & 0.165 & 0.168 & 0.155 & 0.161 \\
H14 & 0.154 & 0.193 & 0.175 & 0.172 & 0.179 \\
\hline
\end{tabular}

the conformers having the $\mathrm{OH} \cdots \mathrm{N}$ hydrogen bonds. However, this is not the case with conformer gGt, which exhibits some angles that are considerably different than those occurring in the remaining conformers. In particular, the $\mathrm{C}-\mathrm{C}-\mathrm{N}$ and $\mathrm{C}-\mathrm{O}-\mathrm{H}$ angles become much smaller $\left(107.5 \mathrm{vs.} \approx 106.0^{\circ}\right.$ and 107.8 vs. $103.2-104.3^{\circ}$, respectively), while the $\mathrm{C}-\mathrm{C}-\mathrm{O}$ angle increases $\left(107.0\right.$ vs. $\left.>110.6^{\circ}\right)$. These differences can easily be correlated with the different type of hydrogen bonding occurring in this conformer and with the different conformation assumed by the hydroxyl group (trans in $\mathbf{g G t}$ vs. gauche in the other forms).

\subsection{Dipole moments and atomic charges}

Both the MP2 and HF predicted dipole moments slightly overestimate the experimental ones (see Table 2), the relative values obtained for the two experimentally studied conformers being very well reproduced by the calculations: $\Delta \mu_{\mathrm{g}^{\prime} \mathrm{Gg}^{\prime}-\mathrm{gG}^{\prime} \mathrm{g}}=$ 0.15 Debye (exp. [4]), 0.16 Debye (HF) and 0.18 Debye (MP2). This result clearly indicates that the electron distribution is calculated at both levels of theory used with enough accuracy to enable prediction of some conformationally related changes in molecular properties using either the MP2 or HF wavefunction. This is the case, for instance, of
Mülliken atomic charges (Table 3), which are almost equal, as calculated at both MP2 or HF levels. ${ }^{2}$

The most relevant changes in the atomic charges with conformation occur for the hydrogen atoms involved in the establishment of the intramolecular hydrogen bonds (i.e. the hydroxylic hydrogen in conformers $\mathbf{g}^{\prime} \mathbf{G g} \mathbf{g}^{\prime}, \mathbf{g G} \mathbf{G}^{\prime} \mathbf{g}, \mathbf{g G g} \mathbf{g}^{\prime}$ and $\mathbf{g}^{\prime} \mathbf{G}^{\prime} \mathbf{g}$, and the H8 amine hydrogen atom in $\mathbf{g G t}$ ). The charge on the hydroxylic hydrogen correlates with the strength of the $\mathrm{OH} \cdots \mathrm{N}$ hydrogen bond, the stronger the hydrogen bond, the more positive the charge of this hydrogen atom (ca. $0.47 e$ in $\mathbf{g}^{\prime} \mathbf{G g}^{\prime}$ and $\mathbf{g G}^{\prime} \mathbf{g}, \approx 0.45 e$ in $\mathbf{g G g} \mathbf{g}^{\prime}$ and $\mathbf{g}^{\prime} \mathbf{G}^{\prime} \mathbf{g}$, and $0.44 e$ in $\left.\mathbf{g G t}\right)$. On the contrary, the charge on the amine hydrogen atom which is involved in the $\mathrm{NH} \cdots \mathrm{O}$ hydrogen bond in gGt (H8) is considerably more positive than those of the remaining amine hydrogen atoms which do not participate in this kind of interaction (0.36e vs. $0.33-0.34 e$ ).

It is also interesting to note that the dipole moment of the conformer gGt is much smaller than those of the remaining forms. This result has important spectroscopic consequences as it will be pointed out later on.

\subsection{Gas phase and matrix-isolation infrared spectra}

No spectroscopic vibrational data have been previously reported for 2AP, except for the gas phase [12,22]. As mentioned before, in their microwave structural study [12], Ellingsen, Marstokk and Møllendal (with no intentions of undertaking a detailed vibrational study of 2AP) identified a few low frequency $(n<250 \mathrm{~cm})$ vibrations of the two conformers they were able to detect $\left(\mathbf{g}^{\prime} \mathbf{G g}^{\prime}\right.$ and $\mathbf{g G}^{\prime} \mathbf{g}$ ). These results fully agree with the results of our calculations, as we shall point out later on. As for Ref. [22], the gas phase spectrum was not even assigned.

In the infrared spectra of the matrix-isolated compound presented in Fig. 2 ( $\mathrm{Ar}$ and $\mathrm{Kr}$ matrices) bands due to five different conformers of $\mathbf{2 A P}$ were observed. Tables 4-8 show the calculated wavenumbers and infrared and Raman intensities of the vibrational bands for the five lowest energy conformers of

\footnotetext{
${ }^{2}$ HF Mülliken atomic charges for all conformers studied are available from the corresponding author upon request.
} 

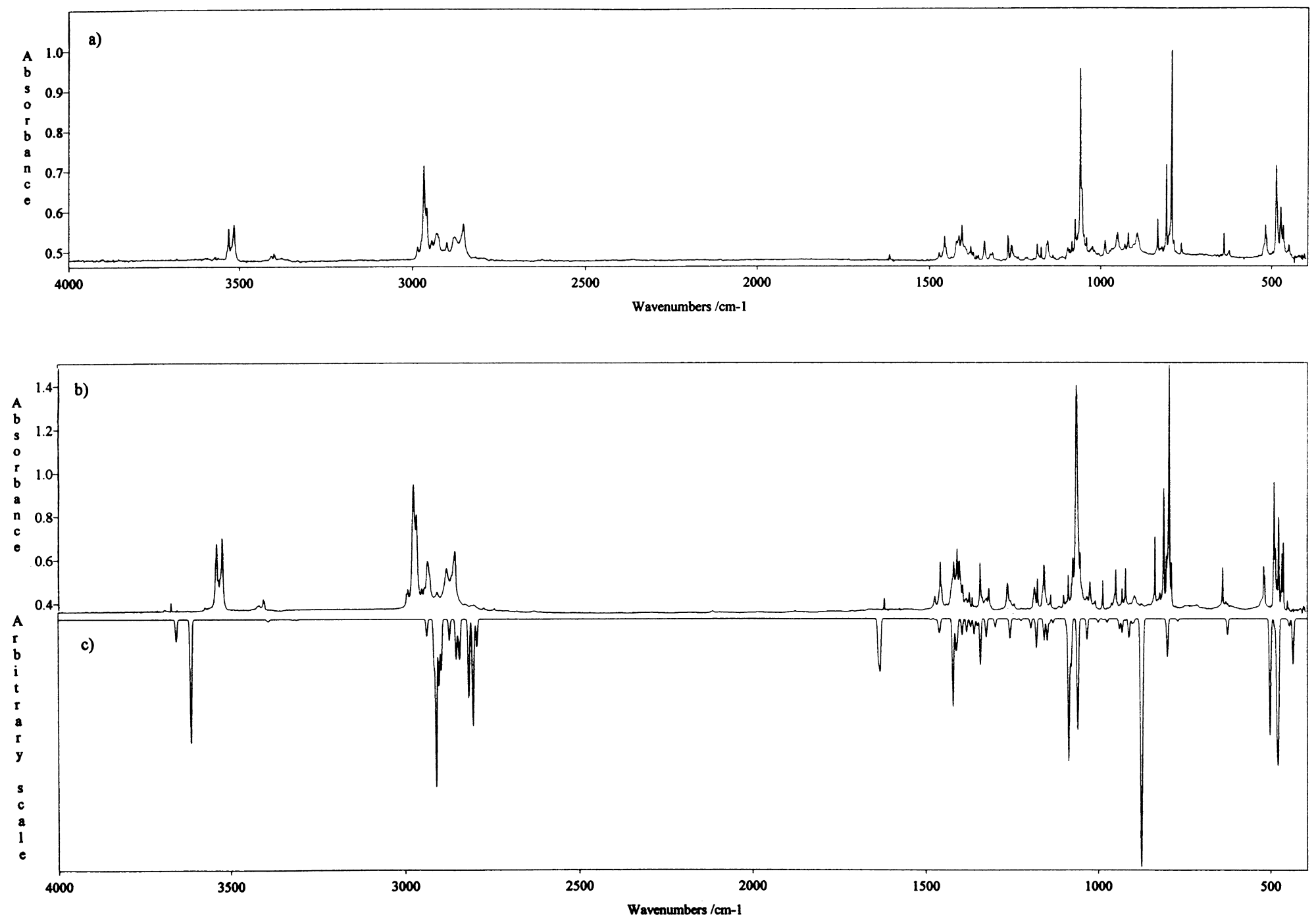

Fig. 2. Low temperature (12 K) infrared spectra of 2-amino-1-propanol isolated in: (a) Kr; (b) Ar; and (c) calculated vibrational spectrum, obtained by gaussian synthesis (constant half band width assumed) using the results presented in Table 9, and shown in an arbitrary scale. 
Table 4

HF 6-31G* calculated wavenumbers and infrared (ir) and Raman (R) intensities as well as calculated Potential Energies Distributions (PEDs) for form $\mathbf{g}^{\prime} \mathbf{G g}^{\prime}$; of 2-amino-1-propanol (wavenumbers $(\nu)$ in $\mathrm{cm}^{-1}$; intensities $(I)$ in $\mathrm{km} \mathrm{mol}^{-1}$ )

\begin{tabular}{|c|c|c|c|c|}
\hline$\nu$ & $I^{\mathrm{ir}}$ & $I^{\mathrm{R}}$ & $\mathrm{PED}^{\mathrm{a}, \mathrm{b}}$ & Assignment ${ }^{\mathrm{b}}$ \\
\hline 4061 & 78.6 & 37.1 & $\nu \mathrm{OH}(100)$ & $\nu \mathrm{OH}$ \\
\hline 3808 & 1.6 & 67.1 & $\nu \mathrm{NH}_{2}$ as.(96) & $\nu \mathrm{NH}_{2}$ as. \\
\hline 3719 & 0.5 & 80.5 & $\nu \mathrm{NH}_{2} \mathrm{~s} .(96)$ & $\nu \mathrm{NH}_{2} \mathrm{~s}$ \\
\hline 3271 & 100.3 & 120.0 & $\nu \mathrm{CH}_{2}$ as. $(47)+\nu \mathrm{CH}_{2}$ s. $(23)+\nu \mathrm{CH}_{3}$ as. ${ }^{\prime}(16)$ & $\nu \mathrm{CH}_{2}$ as. \\
\hline 3262 & 32.0 & 56.0 & $\nu \mathrm{CH}_{3}$ as.'(82) & $\nu \mathrm{CH}_{3}$ as.' \\
\hline 3254 & 40.4 & 12.3 & $\nu \mathrm{CH}_{3}$ as.(69) & $\nu \mathrm{CH}_{3}$ as. \\
\hline 3227 & 17.3 & 95.7 & $\nu \mathrm{CH}(81)+\nu \mathrm{CH}_{3}$ as. $(15)$ & $\nu \mathrm{CH}$ \\
\hline 3193 & 30.2 & 112.8 & $\nu \mathrm{CH}_{3} \mathrm{~s} .(96)$ & $\nu \mathrm{CH}_{3} \mathrm{~s}$ \\
\hline 3149 & 72.4 & 76.7 & $\nu \mathrm{CH}_{2} \mathrm{~s}(62)+\nu \mathrm{CH}_{2}$ as. (36) & $\nu \mathrm{CH}_{2} \mathrm{~s}$ \\
\hline 1833 & 38.0 & 6.1 & $\delta \mathrm{NH}_{2}(73)+\omega \mathrm{NH}_{2}(22)$ & $\delta \mathrm{NH}_{2}$ \\
\hline 1668 & 0.4 & 11.3 & $\delta \mathrm{CH}_{2}(92)$ & $\delta \mathrm{CH}_{2}$ \\
\hline 1643 & 6.2 & 8.9 & $\delta \mathrm{CH}_{3}$ as. ${ }^{\prime}(60)+\delta \mathrm{CH}_{3}$ as. $(20)$ & $\delta \mathrm{CH}_{3}$ as.' \\
\hline 1640 & 3.6 & 13.9 & $\delta \mathrm{CH}_{3}$ as. $(66)+\delta \mathrm{CH}_{3}$ as. $^{\prime}(24)$ & $\delta \mathrm{CH}_{3}$ as. \\
\hline 1597 & 70.1 & 1.5 & $\omega \mathrm{CH}_{2}(50)+\delta \mathrm{COH}(17)$ & $\omega \mathrm{CH}_{2}$ \\
\hline 1566 & 4.8 & 2.8 & $\delta \mathrm{CH}_{3} \mathrm{~s} .(66)+\delta \mathrm{CH}(12)$ & $\delta \mathrm{CH}_{3} \mathrm{~s}$. \\
\hline 1551 & 10.8 & 9.0 & $\delta \mathrm{CH}(44)+\delta \mathrm{CH}_{3} \mathrm{~s} .(18)$ & $\delta \mathrm{CH}$ \\
\hline 1507 & 37.0 & 12.5 & $\delta \mathrm{COH}(29)+\mathrm{twCH}_{2}(23)+\gamma \mathrm{CH}(15)+\omega \mathrm{CH}_{2}(13)$ & $\delta \mathrm{COH}$ \\
\hline 1458 & 6.9 & 2.0 & $\gamma \mathrm{CH}(44)+\omega \mathrm{CH}_{2}(20)$ & $\gamma \mathrm{CH}$ \\
\hline 1412 & 15.8 & 4.7 & $\gamma \mathrm{NH}_{2}(20)+\mathrm{twCH}_{2}(19)+\delta \mathrm{COH}(13)$ & $\gamma \mathrm{NH}_{2}$ \\
\hline 1300 & 17.5 & 3.8 & $\mathrm{twCH}_{2}(30)+\delta \mathrm{COH}(13)$ & $\mathrm{twCH}_{2}$ \\
\hline 1290 & 17.7 & 1.5 & $\gamma \mathrm{CH}_{3}^{\prime}(25)+\nu \mathrm{CN}(17)+\nu$ CCas. $(13)$ & $\nu \mathrm{CN}$ \\
\hline 1219 & 113.1 & 6.1 & $\nu \mathrm{CO}(63)+\delta \mathrm{COH}(13)$ & $\nu \mathrm{CO}$ \\
\hline 1191 & 57.4 & 2.8 & $\nu \mathrm{CN}(21)+\nu \mathrm{CCas} .(19)+\nu \mathrm{CCs} .(18)+\nu \mathrm{CO}(13)$ & $\nu$ CCas. \\
\hline 1125 & 3.1 & 2.1 & $\gamma \mathrm{NH}_{2}(38)+\gamma \mathrm{CH}_{3}(19)+\gamma \mathrm{CH}(15)+\gamma \mathrm{CH}_{2}(13)$ & $\gamma \mathrm{CH}_{3}$ \\
\hline 1024 & 10.0 & 7.0 & $\gamma \mathrm{CH}_{3}{ }^{\prime}(48)+\nu \mathrm{CN}(17)$ & $\gamma \mathrm{CH}_{3}{ }^{\prime}$ \\
\hline 1008 & 2.9 & 3.8 & $\gamma \mathrm{CH}_{2}(38)+\nu$ CCas. $(18)+\gamma \mathrm{CH}_{3}(15)$ & $\gamma \mathrm{CH}_{2}$ \\
\hline 984 & 146.2 & 1.3 & $\omega \mathrm{NH}_{2}(50)+\delta \mathrm{NH}_{2}(13)$ & $\omega \mathrm{NH}_{2}$ \\
\hline 898 & 27.6 & 10.3 & $\nu$ CCs. $(36)+\nu \mathrm{CN}(25)+\gamma \mathrm{CH}_{3}(12)$ & $\nu$ CCs. \\
\hline 564 & 93.1 & 2.7 & $\delta \mathrm{OCC}(27)+\tau \mathrm{HOCC}(27)+\delta \mathrm{CCNs} .(14)+\nu \mathrm{CCs} .(12)$ & $\delta \mathrm{OCC}$ \\
\hline 537 & 96.0 & 3.6 & $\tau \mathrm{HOCC}(51)+\delta \mathrm{CCNs} .(16)$ & $\tau \mathrm{HOCC}$ \\
\hline 488 & 3.0 & 0.6 & $\delta \mathrm{CCNas} .(44)+\tau \mathrm{HOCC}(18)$ & $\delta$ CCNas. \\
\hline 392 & 6.7 & 0.9 & $\delta \mathrm{CCNs} .(44)+\delta \mathrm{CCC}(24)+\gamma \mathrm{CH}_{3}{ }^{\prime}(12)$ & $\delta \mathrm{CCNs}$ \\
\hline 300 & 11.5 & 1.2 & $\tau \mathrm{CCNH}(72)+\tau \mathrm{HOCC}(13)$ & $\tau \mathrm{CCNH}$ \\
\hline 284 & 2.4 & 0.1 & $\delta \mathrm{CCC}(42)+\delta \mathrm{OCC}(30)+\delta \mathrm{CCNs} .(11)$ & $\delta \mathrm{CCC}$ \\
\hline 253 & 0.2 & 0.01 & $\tau \mathrm{CCCH}(88)$ & $\tau \mathrm{CCCH}$ \\
\hline 169 & 5.4 & 0.04 & $\tau \mathrm{OCCN}(78)+\tau \mathrm{HOCC}(15)$ & $\tau \mathrm{OCCN}$ \\
\hline
\end{tabular}

a Only PED values larger than $10 \%$ are shown in this table.

b Abbreviations: $\nu$, stretching; $\delta$, bending; $\gamma$, rocking; $\omega$, wagging; $\tau$, torsion; tw, twisting.

2AP predicted by the ab initio calculations $\left(\mathbf{g}^{\prime} \mathbf{G g}^{\prime}\right.$, $\mathbf{g G} \mathbf{g}^{\prime} \mathbf{g}, \mathbf{g G g} \mathbf{g}^{\prime}, \mathbf{g G t}$ and $\left.\mathbf{g}^{\prime} \mathbf{G}^{\prime} \mathbf{g}\right)$, together with the Potential Energy Distributions (PEDs). The theoretical data, subjected to the usual scaling procedure, (see Section 2) fit nicely to the experimental observations, as can be noticed by comparing the experimental with the simulated spectra also shown in Fig. 2. A detailed assignment of the matrix-isolated and gas phase spectra is presented in Table 9. Note that in the high temperature gas phase spectrum, where bands are much broader than in the matrix isolation spectra and extensive overlapping occurs, only bands due to the three most stable conformers $\left(\mathbf{g}^{\prime} \mathbf{G} \mathbf{g}^{\prime}, \mathbf{g G} \mathbf{g}^{\prime} \mathbf{g}\right.$ and $\mathbf{g G g}^{\prime}$ ) could be unequivocally observed.

As it could be anticipated, bands owing to the conformational ground state $\left(\mathbf{g}^{\prime} \mathbf{G} \mathbf{g}^{\prime}\right)$ dominate the spectrum in the low temperature matrices. The absence of significant contribution of dimers (or 
Table 5

HF 6-31G* calculated wavenumbers and infrared (ir) and Raman (R) intensities as well as calculated Potential Energies Distributions (PEDs) for form $\mathbf{g G}^{\prime} \mathbf{g}$ of 2-amino-1-propanol (wavenumbers $(\nu)$ in $\mathrm{cm}^{-1}$; intensities $(I)$ in $\mathrm{km} \mathrm{mol}^{-1}$ )

\begin{tabular}{|c|c|c|c|c|}
\hline$\nu$ & $I^{\mathrm{ir}}$ & $I^{\mathrm{R}}$ & $\mathrm{PED}^{\mathrm{a}, \mathrm{b}}$ & Assignment ${ }^{\mathrm{b}}$ \\
\hline 4063 & 70.7 & 35.2 & $\nu \mathrm{OH}(100)$ & $\nu \mathrm{OH}$ \\
\hline 3812 & 1.1 & 69.5 & $\nu \mathrm{NH}_{2}$ as.(99) & $\nu \mathrm{NH}_{2}$ as. \\
\hline 3729 & 0.7 & 100.4 & $\nu \mathrm{NH}_{2} \mathrm{~s} .(99)$ & $\nu \mathrm{NH}_{2} \mathrm{~s}$ \\
\hline 3301 & 31.4 & 49.6 & $\nu \mathrm{CH}_{3}$ as.(93) & $\nu \mathrm{CH}_{3}$ as. \\
\hline 3269 & 80.4 & 109.9 & $\nu \mathrm{CH}_{2}$ as. $(50)+\nu \mathrm{CH}_{2}$ s. $(27)+\nu \mathrm{CH}_{3}$ as. $^{\prime}(19)$ & $\nu \mathrm{CH}_{2}$ as. \\
\hline 3261 & 14.1 & 33.0 & $\nu \mathrm{CH}_{3}$ as. $.^{\prime}(74)+\nu \mathrm{CH}_{2}$ as. (14) & $\nu \mathrm{CH}_{3}$ as.' \\
\hline 3206 & 30.3 & 115.7 & $\nu \mathrm{CH}_{3}$ s. $(90)$ & $\nu \mathrm{CH}_{3} \mathrm{~s}$ \\
\hline 3164 & 144.7 & 108.6 & $\nu \mathrm{CH}_{2} \mathrm{~s} .(52)+\nu \mathrm{CH}_{2}$ as. $(31)+\delta \mathrm{CH}_{2}(15)$ & $\nu \mathrm{CH}_{2} \mathrm{~s}$ \\
\hline 3138 & 50.8 & 76.8 & $\nu \mathrm{CH}(81)+\nu \mathrm{CH}_{2} \mathrm{~s} .(12)$ & $\nu \mathrm{CH}$ \\
\hline 1837 & 46.4 & 5.7 & $\delta \mathrm{NH}_{2}(73)+\omega \mathrm{NH}_{2}(23)$ & $\delta \mathrm{NH}_{2}$ \\
\hline 1670 & 0.3 & 7.8 & $\delta \mathrm{CH}_{2}(90)$ & $\delta \mathrm{CH}_{2}$ \\
\hline 1645 & 3.1 & 11.0 & $\delta \mathrm{CH}_{3}$ as.' (84) & $\delta \mathrm{CH}_{3}$ as.' \\
\hline 1639 & 6.3 & 18.0 & $\delta \mathrm{CH}_{3}$ as. (86) & $\delta \mathrm{CH}_{3}$ as. \\
\hline 1586 & 49.5 & 3.0 & $\omega \mathrm{CH}_{2}(47)+\delta \mathrm{CH}_{3} \mathrm{~s} .(23)$ & $\omega \mathrm{CH}_{2}$ \\
\hline 1582 & 33.4 & 1.8 & $\delta \mathrm{CH}_{3}$ s. $(22)+\nu$ CCas. $(18)+\gamma \mathrm{CH}(14) \delta \mathrm{COH}(12)$ & $\gamma \mathrm{CH}$ \\
\hline 1540 & 2.9 & 3.1 & $\delta \mathrm{CH}_{3} \mathrm{~s} .(46)+\gamma \mathrm{CH}(24)+\omega \mathrm{CH}_{2}(12)$ & $\delta \mathrm{CH}_{3} \mathrm{~s}$. \\
\hline 1517 & 13.4 & 7.8 & $\delta \mathrm{CH}(53)+\delta \mathrm{CCNas} .(19)$ & $\delta \mathrm{CH}$ \\
\hline 1488 & 27.0 & 5.1 & $\delta \mathrm{COH}(29)+\omega \mathrm{CH}_{2}(18)+\mathrm{twCH}_{2}(18)$ & $\delta \mathrm{COH}$ \\
\hline 1388 & 1.6 & 14.1 & $\gamma \mathrm{NH}_{2}(27)+\gamma \mathrm{CH}(25)+\mathrm{twCH}_{2}(19)$ & $\gamma \mathrm{NH}_{2}$ \\
\hline 1326 & 53.5 & 4.6 & $\mathrm{twCH}_{2}(30)+\delta \mathrm{COH}(16)+\delta \mathrm{CH}(13)$ & $\mathrm{twCH}_{2}$ \\
\hline 1271 & 8.0 & 3.0 & $\nu \mathrm{CO}(25)+\gamma \mathrm{CH}_{2}(18)$ & $\nu \mathrm{CO}$ \\
\hline 1211 & 56.0 & 2.0 & $\nu \mathrm{CO}(31)+\delta \mathrm{COH}(15)+\nu \mathrm{CN}(12)$ & $\nu \mathrm{CN}$ \\
\hline 1161 & 38.1 & 5.0 & $\gamma \mathrm{NH}_{2}(25)+\gamma \mathrm{CH}_{3}(22)+\nu \mathrm{CO}(15)$ & $\gamma \mathrm{CH}_{3}$ \\
\hline 1095 & 7.1 & 5.3 & $\gamma \mathrm{CH}_{3}^{\prime}(37)+\gamma \mathrm{NH}_{2}(12)+\nu \mathrm{CN}(12)+\nu \mathrm{CC}$ as. $(12)$ & $\gamma \mathrm{CH}_{3}^{\prime}$ \\
\hline 1055 & 18.7 & 5.9 & $\gamma \mathrm{CH}_{2}(27)+\nu \mathrm{CN}(18)+\omega \mathrm{NH}_{2}(13)$ & $\gamma \mathrm{CH}_{2}$ \\
\hline 1024 & 12.0 & 5.8 & $\nu$ CCas.(37) $+\gamma \mathrm{CH}_{2}(23)+\gamma \mathrm{CH}_{3}^{\prime}(17)$ & $\nu$ CCas. \\
\hline 979 & 136.0 & 2.6 & $\omega \mathrm{NH}_{2}(45)+\delta \mathrm{NH}_{2}(12)+\gamma \mathrm{CH}_{3}(12)+\nu \mathrm{CN}(11)$ & $\omega \mathrm{NH}_{2}$ \\
\hline 864 & 4.3 & 12.9 & $\nu \mathrm{CCs} .(65)+\nu \mathrm{CN}(15)$ & $\nu$ CCs. \\
\hline 704 & 29.3 & 1.0 & $\delta \mathrm{OCC}(32)+\delta \mathrm{CCNas} .(16)+\gamma \mathrm{CH}_{3}(11)$ & $\delta$ CCNas. \\
\hline 541 & 185.0 & 2.5 & $\tau \mathrm{HOCC}(85)$ & $\tau \mathrm{HOCC}$ \\
\hline 441 & 0.4 & 0.6 & $\delta$ CCNs.(58) & $\delta \mathrm{CCNs}$ \\
\hline 404 & 10.7 & 0.4 & $\delta \mathrm{CCC}(51)+\delta \mathrm{CCNas} .(19)$ & $\delta \mathrm{CCC}$ \\
\hline 316 & 6.6 & 0.5 & $\tau \mathrm{CCNH}(62)+\tau \mathrm{HOCC}(14)$ & $\tau \mathrm{CCNH}$ \\
\hline 288 & 6.2 & 0.7 & $\tau \mathrm{CCNH}(32)+\delta \mathrm{OCC}(31)+\delta \mathrm{CCC}(16)$ & $\delta \mathrm{OCC}$ \\
\hline 244 & 3.6 & 0.1 & $\tau \mathrm{CCCH}(77)$ & $\tau \mathrm{CCCH}$ \\
\hline 163 & 5.6 & 0.1 & $\tau \mathrm{OCCN}(72)+\tau \mathrm{HOCC}(15)$ & $\tau \mathrm{OCCN}$ \\
\hline
\end{tabular}

a Only PED values larger than $10 \%$ are shown in this table.

b Abbreviations: $\nu$, stretching; $\delta$, bending; $\gamma$, rocking; $\omega$, wagging; $\tau$, torsion; tw, twisting.

higher order aggregates) to the observed spectra was confirmed by comparison with spectra obtained using low matrix/solute ratios (the most intense band of aggregated species, which is not observed at all, should be present around $3260 \mathrm{~cm}^{-1}$ ). Most of the bands expected for conformers $\mathbf{g G}^{\prime} \mathbf{g}, \mathbf{g G g} \mathbf{g}^{\prime}, \mathbf{g G t}$ and $\mathbf{g}^{\prime} \mathbf{G}^{\prime} \mathbf{g}$ could also be observed both in argon and krypton. Some of the bands, in particular those ascribable to the hydroxyl and amine groups (see Table 9), appear as doublets due to matrix site effects (in Ar, the
$\mathrm{OH}$ stretching of conformer $\mathbf{g}^{\prime} \mathbf{G} \mathbf{g}^{\prime}$ gives rise to a triplet). An estimation of the relative populations of the observed conformers in $\mathrm{Ar}$ and $\mathrm{Kr}$ can be obtained by comparing the calculated and observed intensities in the corresponding spectra. As band intensities were not found to change upon annealing of the matrices up to $30 \mathrm{~K}$, the conformational composition measured by this way must be similar to that of the initial gaseous mixture, which was kept at $298 \mathrm{~K}$. Considering all the possible bands for each conformer, population ratios 
Table 6

HF 6-31G* calculated wavenumbers and infrared (ir) and Raman (R) intensities as well as calculated Potential Energies Distributions (PEDs) for form $\mathbf{g G g} \mathbf{g}^{\prime}$; of 2-amino-1-propanol (wavenumbers $(\nu)$ in $\mathrm{cm}^{-1}$; intensities $(I)$ in $\mathrm{km} \mathrm{mol}^{-1}$ )

\begin{tabular}{|c|c|c|c|c|}
\hline$\nu$ & $I^{\mathrm{ir}}$ & $I^{\mathrm{R}}$ & $\mathrm{PED}^{\mathrm{a}, \mathrm{b}}$ & Assignment $\mathrm{t}^{\mathrm{b}}$ \\
\hline 4110 & 49.5 & 47.7 & $\nu \mathrm{OH}(100)$ & $\nu \mathrm{OH}$ \\
\hline 3813 & 1.3 & 65.7 & $\nu \mathrm{NH}_{2}$ as.(100) & $\nu \mathrm{NH}_{2}$ as. \\
\hline 3734 & 0.7 & 93.9 & $\nu \mathrm{NH}_{2} \mathrm{~s} .(100)$ & $\nu \mathrm{NH}_{2} \mathrm{~s}$ \\
\hline 3278 & 100.1 & 100.1 & $\nu \mathrm{CH}_{3}$ as. (43) $+\nu \mathrm{CH}_{2}$ as. (39) & $\nu \mathrm{CH}_{2}$ as. \\
\hline 3268 & 8.0 & 28.9 & $\nu \mathrm{CH}_{3}$ as.(47) $+\nu \mathrm{CH}_{2}$ as. (39) & $\nu \mathrm{CH}_{3}$ as. \\
\hline 3261 & 45.3 & 62.7 & $\nu \mathrm{CH}_{3}$ as. '(89) & $\nu \mathrm{CH}_{3}$ as.' \\
\hline 3204 & 55.3 & 161.5 & $\nu \mathrm{CH}_{3} \mathrm{~s} .(61)+\nu \mathrm{CH}_{2} \mathrm{~s} .(30)$ & $\nu \mathrm{CH}_{3} \mathrm{~s}$ \\
\hline 3198 & 36.4 & 9.1 & $\nu \mathrm{CH}_{2}$ s. $(50)+\nu \mathrm{CH}_{3}$ s. $(37)+\nu \mathrm{CH}_{2}$ as. (11) & $\nu \mathrm{CH}_{2} \mathrm{~s}$ \\
\hline 3151 & 56.4 & 108.7 & $\nu \mathrm{CH}(96)$ & $\nu \mathrm{CH}$ \\
\hline 1839 & 44.2 & 5.2 & $\delta \mathrm{NH}_{2}(74)+\omega \mathrm{NH}_{2}(22)$ & $\delta \mathrm{NH}_{2}$ \\
\hline 1654 & 2.4 & 13.2 & $\delta \mathrm{CH}_{2}(90)$ & $\delta \mathrm{CH}_{2}$ \\
\hline 1648 & 1.7 & 10.5 & $\delta \mathrm{CH}_{3}$ as. $.^{\prime}(63)+\delta \mathrm{CH}_{3}$ as. (21) & $\delta \mathrm{CH}_{3}$ as. $^{\prime}$ \\
\hline 1639 & 3.6 & 12.5 & $\delta \mathrm{CH}_{3}$ as. $(66)+\delta \mathrm{CH}_{3}$ as.' (19) & $\delta \mathrm{CH}_{3}$ as. \\
\hline 1590 & 10.4 & 1.0 & $\omega \mathrm{CH}_{2}(45)+\gamma \mathrm{CH}(14)$ & $\omega \mathrm{CH}_{2}$ \\
\hline 1566 & 23.7 & 2.2 & $\delta \mathrm{CH}_{3}$ s.(70) & $\delta \mathrm{CH}_{3} \mathrm{~s}$. \\
\hline 1538 & 16.6 & 10.1 & $\delta \mathrm{CH}(42)+\mathrm{twCH}_{2}(18)+\delta \mathrm{CCNas} .(19)$ & $\delta \mathrm{CH}$ \\
\hline 1527 & 34.7 & 5.4 & $\delta \mathrm{COH}(35)+\mathrm{twCH}_{2}(20)+\delta \mathrm{CH}(18)$ & $\mathrm{twCH}_{2}$ \\
\hline 1488 & 8.8 & 2.7 & $\omega \mathrm{CH}_{2}(37)+\gamma \mathrm{CH}(33)$ & $\gamma \mathrm{CH}$ \\
\hline 1375 & 4.1 & 11.3 & $\gamma \mathrm{NH}_{2}(38)+\gamma \mathrm{CH}(22)+\mathrm{twCH}_{2}(11)$ & $\gamma \mathrm{NH}_{2}$ \\
\hline 1344 & 21.6 & 2.9 & $\mathrm{twCH}_{2}(31)+\delta \mathrm{COH}(20)+\gamma \mathrm{CH}_{3}(11)$ & $\gamma \mathrm{CH}_{3}$ \\
\hline 1282 & 10.5 & 5.5 & $\nu \mathrm{CN}(24)+\nu \mathrm{CCs} .(19)+\gamma \mathrm{CH}_{3}{ }^{\prime}(16)+\delta \mathrm{CCC}(11)$ & $\nu \mathrm{CN}$ \\
\hline 1213 & 39.5 & 6.2 & $\nu \mathrm{CO}(55)$ & $\nu \mathrm{CO}$ \\
\hline 1189 & 110.0 & 2.3 & $\nu \mathrm{CO}(31)+\delta \mathrm{COH}(21)$ & $\delta \mathrm{COH}$ \\
\hline 1107 & 2.3 & 5.0 & $\nu$ CCas. $(31)+\gamma \mathrm{NH}_{2}(25)+\gamma \mathrm{CH}_{3}^{\prime}(17)$ & $\nu$ CCas. \\
\hline 1047 & 31.3 & 5.5 & $\gamma \mathrm{CH}_{3}^{\prime}(26)+\omega \mathrm{NH}_{2}(24)+\nu$ CCas. $(23)$ & $\gamma \mathrm{CH}_{3}{ }^{\prime}$ \\
\hline 1014 & 10.6 & 2.0 & $\gamma \mathrm{CH}_{2}(30)+\gamma \mathrm{CH}_{3}(24)+\nu$ CCas. $(11)$ & $\gamma \mathrm{CH}_{2}$ \\
\hline 984 & 113.3 & 2.3 & $\omega \mathrm{NH}_{2}(36)+\gamma \mathrm{CH}_{2}(16)+\nu \mathrm{CN}(10)$ & $\omega \mathrm{NH}_{2}$ \\
\hline 900 & 11.2 & 9.5 & $\nu \mathrm{CCs} .(35)+\nu \mathrm{CN}(27)+\gamma \mathrm{CH}_{3}(13)$ & $\nu$ CCs. \\
\hline 550 & 18.6 & 3.1 & $\delta \mathrm{OCC}(37)+\delta \mathrm{CCNs} .(26)+\nu \mathrm{CCs} .(11)$ & $\delta \mathrm{OCC}$ \\
\hline 502 & 16.9 & 1.3 & $\delta \mathrm{CCNas} .(44)+\tau \mathrm{HOCC}(13)$ & $\delta$ CCNas. \\
\hline 490 & 96.3 & 1.5 & $\tau \mathrm{HOCC}(67)+\tau \mathrm{CCNH}(12)$ & $\tau \mathrm{HOCC}$ \\
\hline 393 & 0.04 & 0.4 & $\delta \mathrm{CCNs} .(47)+\delta \mathrm{CCC}(27)+\gamma \mathrm{CH}_{3}{ }^{\prime}(10)$ & $\delta \mathrm{CCNs}$ \\
\hline 278 & 7.6 & 0.1 & $\delta \mathrm{CCC}(41)+\delta \mathrm{OCC}(36)$ & $\delta \mathrm{CCC}$ \\
\hline 259 & 6.2 & 0.2 & $\tau \mathrm{CCCH}(85)$ & $\tau \mathrm{CCCH}$ \\
\hline 205 & 98.1 & 2.2 & $\tau \mathrm{CCNH}(61)+\tau \mathrm{HOCC}(28)$ & $\tau \mathrm{CCNH}$ \\
\hline 134 & 24.2 & 0.4 & $\tau \mathrm{OCCNH}(53)+\tau \mathrm{HOCC}(26)+\tau \mathrm{CCNH}(12)$ & $\tau \mathrm{OCCN}$ \\
\hline
\end{tabular}

a Only PED values larger than $10 \%$ are shown in this table.

b Abbreviations: $\nu$, stretching; $\delta$, bending; $\gamma$, rocking; $\omega$, wagging; $\tau$, torsion; tw, twisting.

$\left(\mathbf{g}^{\prime} \mathbf{G g}^{\prime}\right.$ : $\mathbf{g G}^{\prime} \mathbf{g}: \mathbf{g G g}$ : $\left.\mathbf{g G t}: \mathbf{g}^{\prime} \mathbf{G}^{\prime} \mathbf{g}\right)$ in $\mathrm{Ar}$ and $\mathrm{Kr}$ were calculated, being 1:0.44:0.36:0.10:0.09 and 1:0.32:0.24:0.08:0.10, respectively. From these results, the following conclusions can be drawn:

(i) The experimentally observed relative populations of the two most stable conformers agree very well with the previous value obtained by microwave spectroscopy $\left(\mathrm{p}_{\mathrm{gG}^{\prime} \mathrm{g} / \mathrm{pg}^{\prime} \mathrm{Gg}^{\prime}}=0.34\right.$ [12]) and fairly well with the calculated values (HF: 0.49 ; MP2: 0.67), despite the fact that the calculations seem to underestimate in some extent the population of the most stable conformer.

(ii) The population of the most stable conformer (with the largest dipole moment) increases in the Kr matrix. This result agrees with the well known tendency for stabilization of more polar species in krypton, due to the higher polarizability of this 
Table 7

HF 6-31G* calculated wavenumbers and infrared (ir) and Raman (R) intensities as well as calculated Potential Energies Distributions (PEDs) for form gGt of 2-amino-1-propanol (wavenumbers $(\nu)$ in $\mathrm{cm}^{-1}$; intensities $(I)$ in $\mathrm{km} \mathrm{mol}^{-1}$ )

\begin{tabular}{|c|c|c|c|c|}
\hline$\nu$ & $I^{\mathrm{ir}}$ & $I^{\mathrm{R}}$ & $\mathrm{PED}^{\mathrm{a}, \mathrm{b}}$ & Assignment $^{\mathrm{b}}$ \\
\hline 4122 & 53.2 & 107.6 & $\nu \mathrm{OH}(100)$ & $\nu \mathrm{OH}$ \\
\hline 2819 & 3.3 & 64.3 & $\nu \mathrm{NH}_{2}$ as.(99) & $\nu \mathrm{NH}_{2}$ as. \\
\hline 3733 & 2.7 & 99.3 & $\nu \mathrm{NH}_{2} \mathrm{~s} .(99)$ & $\nu \mathrm{NH}_{2} \mathrm{~s}$ \\
\hline 3276 & 57.2 & 58.4 & $\nu \mathrm{CH}_{3}$ as. $(96)$ & $\nu \mathrm{CH}_{3}$ as. \\
\hline 3260 & 53.2 & 73.0 & $\nu \mathrm{CH}_{3}$ as.' $(97)$ & $\nu \mathrm{CH}_{3} \mathrm{as}^{\prime}$. \\
\hline 3230 & 70.9 & 31.8 & $\nu \mathrm{CH}_{2}$ as. $(93)$ & $\nu \mathrm{CH}_{2}$ as. \\
\hline 3204 & 41.0 & 151.1 & $\nu \mathrm{CH}_{3} \mathrm{~s} .(93)$ & $\nu \mathrm{CH}_{3} \mathrm{~S}$ \\
\hline 3187 & 49.4 & 47.8 & $\nu \mathrm{CH}_{2}$ s.(89) & $\nu \mathrm{CH}_{2} \mathrm{~s}$. \\
\hline 3140 & 63.5 & 107.3 & $\nu \mathrm{CH}(97)$ & $\nu \mathrm{CH}$ \\
\hline 1834 & 47.9 & 5.5 & $\delta \mathrm{NH}_{2}(74)+\omega \mathrm{NH}_{2}(22)$ & $\delta \mathrm{NH}_{2}$ \\
\hline 1668 & 5.4 & 10.4 & $\delta \mathrm{CH}_{2}(93)$ & $\delta \mathrm{CH}_{2}$ \\
\hline 1648 & 0.9 & 7.5 & $\delta \mathrm{CH}_{3}$ as.' (65) & $\delta \mathrm{CH}_{3}$ as.' \\
\hline 1642 & 4.0 & 15.4 & $\delta \mathrm{CH}_{3}$ as. $(81)$ & $\delta \mathrm{CH}_{3}$ as. \\
\hline 1616 & 0.3 & 4.2 & $\omega \mathrm{CH}_{2}(44)+\delta \mathrm{CH}_{3}$ as.'(19) & $\omega \mathrm{CH}_{2}$ \\
\hline 1570 & 7.1 & 1.5 & $\delta \mathrm{CH}_{3}$ s. $(71)$ & $\delta \mathrm{CH}_{3} \mathrm{~s}$. \\
\hline 1538 & 21.6 & 8.9 & $\delta \mathrm{CH}(48)+\delta \mathrm{CCNas} .(18)$ & $\delta \mathrm{CH}$ \\
\hline 1515 & 4.1 & 1.8 & $\gamma \mathrm{CH}(35)+\delta \mathrm{CH}_{3} \mathrm{~s} .(17)+\gamma \mathrm{NH}_{2}(12)$ & $\gamma \mathrm{CH}$ \\
\hline 1411 & 2.2 & 18.1 & $\mathrm{twCH}_{2}(63)+\gamma \mathrm{NH}_{2}(13)$ & $\mathrm{twCH}_{2}$ \\
\hline 1381 & 63.3 & 5.2 & $\delta \mathrm{COH}(37)+\omega \mathrm{CH}_{2}(17)$ & $\delta \mathrm{COH}$ \\
\hline 1358 & 10.4 & 2.6 & $\gamma \mathrm{NH}_{2}(28)+\gamma \mathrm{CH}(20)+\mathrm{twCH}_{2}(13)$ & $\gamma \mathrm{NH}_{2}$ \\
\hline 1269 & 14.5 & 3.4 & $\nu \mathrm{CN}(30)+\gamma \mathrm{CH}_{2}(22)+\delta \mathrm{CH}(12)$ & $\nu \mathrm{CN}$ \\
\hline 1226 & 78.3 & 3.4 & $\delta \mathrm{COH}(26)+\nu \mathrm{CCs} .(15)+\gamma \mathrm{CH}_{3}(13)$ & $\gamma \mathrm{CH}_{3}$ \\
\hline 1193 & 61.5 & 8.0 & $\nu \mathrm{CO}(83)$ & $\nu \mathrm{CO}$ \\
\hline 1119 & 1.3 & 4.0 & $\nu$ CCas. $(28)+\gamma \mathrm{NH}_{2}(26)+\gamma \mathrm{CH}_{3}^{\prime}(21)$ & $\nu$ CCas. \\
\hline 1037 & 2.0 & 2.2 & $\gamma \mathrm{CH}_{2}(31)+\gamma \mathrm{CH}_{3}(22)+\nu \mathrm{CCas} .(17)+\gamma \mathrm{CH}(11)$ & $\gamma \mathrm{CH}_{2}$ \\
\hline 1036 & 9.4 & 5.4 & $\gamma \mathrm{CH}_{2}^{\prime}(26)+\nu \mathrm{CCas} .(23)+\nu \mathrm{CN}(12)+\omega \mathrm{NH}_{2}(11)$ & $\gamma \mathrm{CH}_{3}{ }^{\prime}$ \\
\hline 986 & 162.3 & 3.4 & $\omega \mathrm{NH}_{2}(46)+\delta \mathrm{NH}_{2}(13)+\nu \mathrm{CN}(12)$ & $\omega \mathrm{NH}_{2}$ \\
\hline 903 & 5.5 & 10.4 & $\nu$ CCs.(39) $+\nu \mathrm{CN}(20)+\gamma \mathrm{CH}_{3}$ & $\nu \mathrm{CCs}$ \\
\hline 541 & 19.8 & 2.1 & $\delta \mathrm{OCC}(31)+\delta \mathrm{CCNs} .(25)+\nu \mathrm{CCs} .(15)$ & $\delta \mathrm{OCC}$ \\
\hline 507 & 7.4 & 0.8 & $\delta$ CCNas.(55) & $\delta$ CCNas. \\
\hline 400 & 6.4 & 0.5 & $\delta \mathrm{CCNs} .(43)+\delta \mathrm{CCC}(22)$ & $\delta$ CCNs. \\
\hline 343 & 43.3 & 2.3 & $\pi \mathrm{CCNH}(76)$ & $\tau \mathrm{CCNH}$ \\
\hline 282 & 27.8 & 0.02 & $\delta \mathrm{OCC}(33)+\delta \mathrm{CCC}(31)+\tau \mathrm{CCNH}(12)$ & $\delta \mathrm{CCC}$ \\
\hline 270 & 136.6 & 2.8 & $\tau \mathrm{HOCC}(83)$ & $\tau \mathrm{HOCC}$ \\
\hline 249 & 0.5 & 0.05 & $\tau \mathrm{CCCH}(85)$ & $\tau \mathrm{CCCH}$ \\
\hline 163 & 3.6 & 0.03 & $\tau \mathrm{OCCN}(92)$ & $\tau \mathrm{OCCN}$ \\
\hline
\end{tabular}

a Only PED values larger than $10 \%$ are shown in this table.

b Abbreviations: $\nu$, stretching; $\delta$, bending; $\gamma$, rocking; $\omega$, wagging; $\tau$, torsion; tw, twisting.

atom when compared with argon, and it also seems to indicate that partial isomerization of the solute takes place during the deposition process.

(iii) in the case of some low intensity bands ascribed to the less stable observed conformers, extensive overlapping makes the band deconvolution process used to determine intensities extremely difficult. Taking these difficulties into account, the agreement between experimental and predicted populations for conformers $\mathbf{g G t}$ and $\mathbf{g}^{\prime} \mathbf{G}^{\prime} \mathbf{g}$ may be considered reasonable (calculated relative populations to the most stable conformer are: HF 0.08 , 0.02 ; MP2: $0.02,0.01)$. On the contrary, the experimentally observed population of form $\mathbf{g G g}{ }^{\prime}$ is much higher than the predicted values (calculated relative populations to the most stable conformer: HF 0.05; MP2: 0.02). This result seems to indicate that the calculations considerably overestimate the energy 
Table 8

HF 6-31G* calculated wavenumbers and infrared (ir) and Raman (R) intensities as well as calculated Potential Energies Distributions (PEDs) for form $\mathbf{g}^{\prime} \mathbf{G}^{\prime} \mathbf{g}$ of 2-amino-1-propanol (wavenumbers $(\nu)$ in $\mathrm{cm}^{-1}$; intensities $(I)$ in $\mathrm{km} \mathrm{mol}^{-1}$ )

\begin{tabular}{|c|c|c|c|c|}
\hline$\nu$ & $I^{\mathrm{ir}}$ & $I^{\mathrm{R}}$ & $\mathrm{PED}^{\mathrm{a}, \mathrm{b}}$ & Assignment $^{\mathrm{b}}$ \\
\hline 4105 & 50.6 & 47.4 & $\nu \mathrm{OH}(100)$ & $\nu \mathrm{OH}$ \\
\hline 3809 & 1.3 & 64.1 & $\nu \mathrm{NH}_{2}$ as.(98) & $\nu \mathrm{NH}_{2}$ as. \\
\hline 3726 & 0.5 & 77.0 & $\nu \mathrm{NH}_{2} \mathrm{~s} .(98)$ & $\nu \mathrm{NH}_{2} \mathrm{~s}$ \\
\hline 3276 & 77.2 & 101.6 & $\nu \mathrm{CH}_{2}$ as. $(68)+\nu \mathrm{CH}_{2} \mathrm{~s} .(14)+\nu \mathrm{CH}_{3}$ as. (12) & $\nu \mathrm{CH}_{2}$ as. \\
\hline 3271 & 43.4 & 24.8 & $\nu \mathrm{CH}_{3}$ as. $(84)+\nu \mathrm{CH}_{2}$ as. (12) & $\nu \mathrm{CH}_{3}$ as. \\
\hline 3256 & 37.0 & 57.7 & $\nu \mathrm{CH}_{3}$ as.'(94) & $\nu \mathrm{CH}_{3}$ as.' \\
\hline 3222 & 80.1 & 166.0 & $\nu \mathrm{CH}_{2} \mathrm{~s} .(43)+\nu \mathrm{CH}(42)$ & $\nu \mathrm{CH}_{2} \mathrm{~s}$ \\
\hline 3202 & 24.1 & 56.9 & $\nu \mathrm{CH}(47)+\nu \mathrm{CH}_{2} \mathrm{~s} .(40)$ & $\nu \mathrm{CH}$ \\
\hline 3197 & 29.4 & 79.5 & $\nu \mathrm{CH}_{3} \mathrm{~s} .(92)$ & $\nu \mathrm{CH}_{3} \mathrm{~s}$ \\
\hline 1836 & 33.9 & 5.4 & $\delta \mathrm{NH}_{2}(74)+\omega \mathrm{NH}_{2}(22)$ & $\delta \mathrm{NH}_{2}$ \\
\hline 1660 & 0.4 & 7.4 & $\delta \mathrm{CH}_{2}(85)$ & $\delta \mathrm{CH}_{2}$ \\
\hline 1647 & 3.6 & 8.2 & $\delta \mathrm{CH}_{3}$ as. $^{\prime}(77)$ & $\delta \mathrm{CH}_{3}$ as.' \\
\hline 1637 & 4.9 & 20.1 & $\delta \mathrm{CH}_{3}$ as. $(76)$ & $\delta \mathrm{CH}_{3}$ as. \\
\hline 1574 & 23.7 & 3.4 & $\delta \mathrm{CH}_{3}$ s. $(37)+\omega \mathrm{CH}_{2}(37)$ & $\delta \mathrm{CH}_{3} \mathrm{~s}$. \\
\hline 1555 & 34.4 & 1.0 & $\omega \mathrm{CH}_{2}(38)+\delta \mathrm{CH}_{3} \mathrm{~s} .(24)$ & $\omega \mathrm{CH}_{2}$ \\
\hline 1547 & 5.9 & 5.6 & $\delta \mathrm{CH}(38)+\delta \mathrm{CH}_{3} \mathrm{~s} .(20)+\gamma \mathrm{NH}_{2}(12)$ & $\delta \mathrm{CH}$ \\
\hline 1528 & 15.0 & 8.3 & $\delta \mathrm{COH}(31)+\mathrm{twCH}_{2}(29)$ & $\delta \mathrm{COH}$ \\
\hline 1489 & 12.3 & 7.0 & $\gamma \mathrm{CH}(53)$ & $\gamma \mathrm{CH}$ \\
\hline 1376 & 10.3 & 4.1 & $\gamma \mathrm{NH}_{2}(26)+\mathrm{twCH}_{2}(20)+\nu \mathrm{CN}(13)$ & $\gamma \mathrm{NH}_{2}$ \\
\hline 1335 & 15.4 & 3.6 & $\mathrm{twCH}_{2}(25)+\delta \mathrm{COH}(15)+\nu \mathrm{CCas} .(11)$ & $\mathrm{twCH}_{2}$ \\
\hline 1278 & 20.7 & 4.7 & $\nu \mathrm{CO}(25)+\gamma \mathrm{CH}_{3}^{\prime}(11)$ & $\gamma \mathrm{CH}_{3}{ }^{\prime}$ \\
\hline 1192 & 68.6 & 2.8 & $\delta \mathrm{COH}(23)+\nu \mathrm{CCas} .(14)+\gamma \mathrm{CH}_{2}(13)+\nu \mathrm{CN}(11)$ & $\nu$ CCas. \\
\hline 1159 & 48.4 & 4.5 & $\nu \mathrm{CO}(46)+\gamma \mathrm{NH}_{2}(20)+\gamma \mathrm{CH}(11)$ & $\nu \mathrm{CO}$ \\
\hline 1096 & 24.5 & 6.9 & $\nu \mathrm{CN}(31)+\gamma \mathrm{CH}_{3}^{\prime}(21)+\gamma \mathrm{CH}_{3}(16)$ & $\nu \mathrm{CN}$ \\
\hline 1040 & 18.4 & 5.1 & $\gamma \mathrm{CH}_{3}(27)+\gamma \mathrm{CH}_{3}^{\prime}(17)$ & $\gamma \mathrm{CH}_{3}$ \\
\hline 1005 & 12.5 & 3.5 & $\gamma \mathrm{CH}_{2}(45)+\nu$ CCas. $(21)$ & $\gamma \mathrm{CH}_{2}$ \\
\hline 1000 & 148.2 & 2.2 & $\omega \mathrm{NH}_{2}(48)+\delta \mathrm{NH}_{2}(13)+\nu \mathrm{CN}(12)$ & $\omega \mathrm{NH}_{2}$ \\
\hline 861 & 6.9 & 13.9 & $\nu \mathrm{CCs} .(69)+\nu \mathrm{CN}(15)$ & $\nu$ CCs. \\
\hline 690 & 14.4 & 1.0 & $\delta \mathrm{OCC}(33)+\delta \mathrm{CCNas} .(19)+\gamma \mathrm{CH}_{3}(12)$ & $\delta$ CCNas. \\
\hline 503 & 124.1 & 1.7 & $\tau \mathrm{HOCC}(82)$ & $\tau \mathrm{HOCC}$ \\
\hline 448 & 9.3 & 1.5 & $\delta \mathrm{CCNs} .(60)$ & $\delta$ CCNs. \\
\hline 397 & 3.8 & 0.1 & $\delta \mathrm{CCC}(58)+\delta \mathrm{CCNas} .(18)$ & $\delta \mathrm{CCC}$ \\
\hline 301 & 2.0 & 0.2 & $\delta \mathrm{OCC}(35)+\tau \mathrm{CCCH}(28)+\delta \mathrm{CCNas} .(16)$ & $\delta \mathrm{OCC}$ \\
\hline 254 & 4.1 & 0.1 & $\tau \mathrm{CCCH}(57)+\delta \mathrm{OCC}(15)+\delta \mathrm{CCC}(14)$ & $\tau \mathrm{CCCH}$ \\
\hline 201 & 102.0 & 2.7 & $\tau \mathrm{CCNH}(58)+\tau \mathrm{HOCC}(33)$ & $\tau \mathrm{CCNH}$ \\
\hline 131 & 12.3 & 0.03 & $\tau \mathrm{OCCN}(70)+\tau \mathrm{HOCC}(16)$ & $\tau \mathrm{OCCN}$ \\
\hline
\end{tabular}

a Only PED values larger than $10 \%$ are shown in this table.

b Abbreviations: $\nu$, stretching; $\delta$, bending; $\gamma$, rocking; $\omega$, wagging; $\tau$, torsion; tw, twisting.

of conformer $\mathbf{g G g}$, though we cannot discard a possible minor contribution to the deviation found between the experimental and calculated results due to the uncertainty in measuring some experimental intensities (e.g. bands ascribed to this conformer in the complex $\mathrm{CH}$ stretching spectral region-see Table 9).

(iv) Very interestingly, and in agreement with ii), the relative population of the less polar of the observed conformers (gGt) decreases when going from the argon to the krypton matrix in such a way that it becomes slightly less populated that form $\mathbf{g}^{\prime} \mathbf{G}^{\prime} \mathbf{g}$.

In spite of the impossibility of presenting here a detailed discussion of the band assignments, some specific spectral regions deserve further comments: 


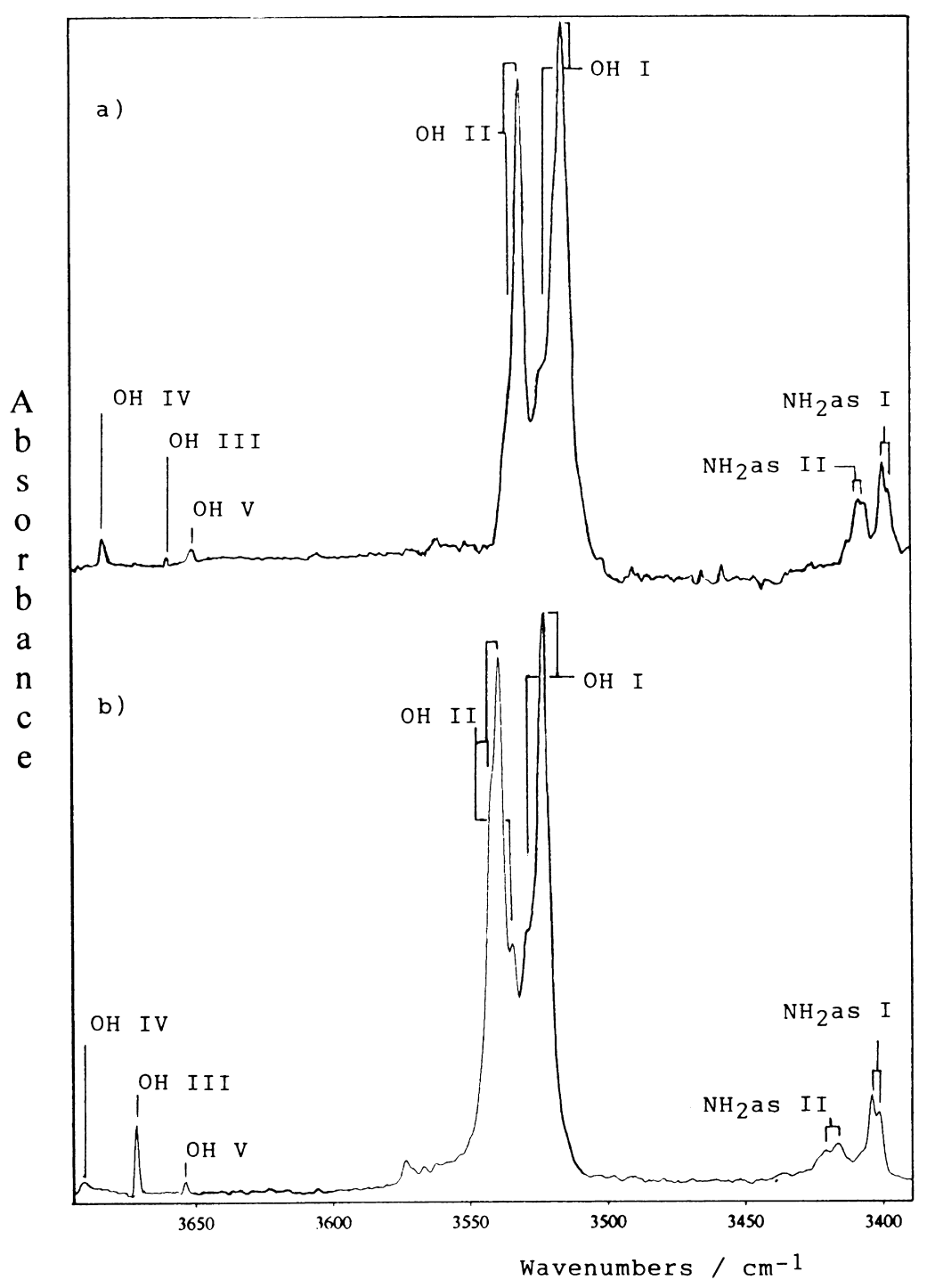

Fig. 3. $\mathrm{OH}$ and $\mathrm{NH}_{2}$ stretching regions of the infrared spectra of 2-amino-1-propanol isolated in $a$ ) $\mathrm{Kr}, b$ ) Ar.

\subsubsection{OH stretching region}

The analysis of this spectral region is, as usually, complicated by the presence of bands due to isolated monomeric molecules of water. It was, however, possible to assign unequivocally the $\mathrm{OH}$ stretching vibration, $\nu \mathrm{OH}$, originated in each of the five observed conformers of $\mathbf{2 A P}$. It is worth mentioning that in all cases $\nu \mathrm{OH}$ is red shifted in krypton, in agreement with relative polarity of the argon and krypton matrices (see Table 9 and Fig. 3). In the gas phase spectrum only two bands assigned to the $\nu \mathrm{OH}$ vibration are observed, the lowest frequency band containing contributions of conformers $\mathbf{g}^{\prime} \mathbf{G} \mathbf{g}^{\prime}$ (main component) and $\mathbf{g G}^{\prime} \mathbf{g}$, and the less intense highest frequency band being ascribable, essentially, to the $\mathbf{g G g}^{\prime}$ form, though it must possess also minor contributions from conformers $\mathbf{g G t}$ and $\mathbf{g}^{\prime} \mathbf{G}^{\prime} \mathbf{g}$. As expected, the frequencies of these bands are slightly higher than the corresponding ones observed in the matrices.

In Fig. 4, a correlation between the observed 


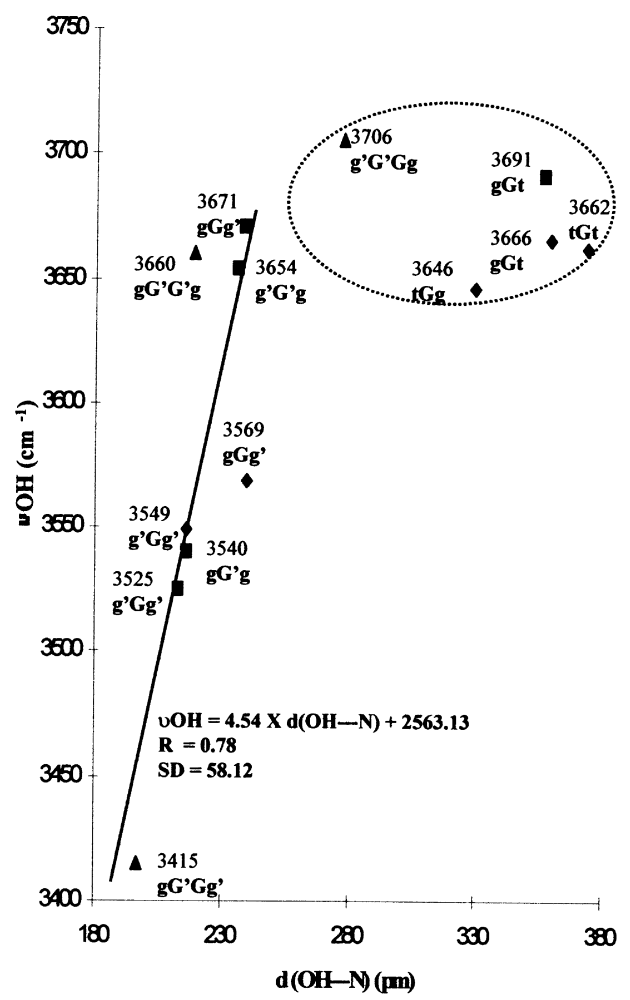

a)

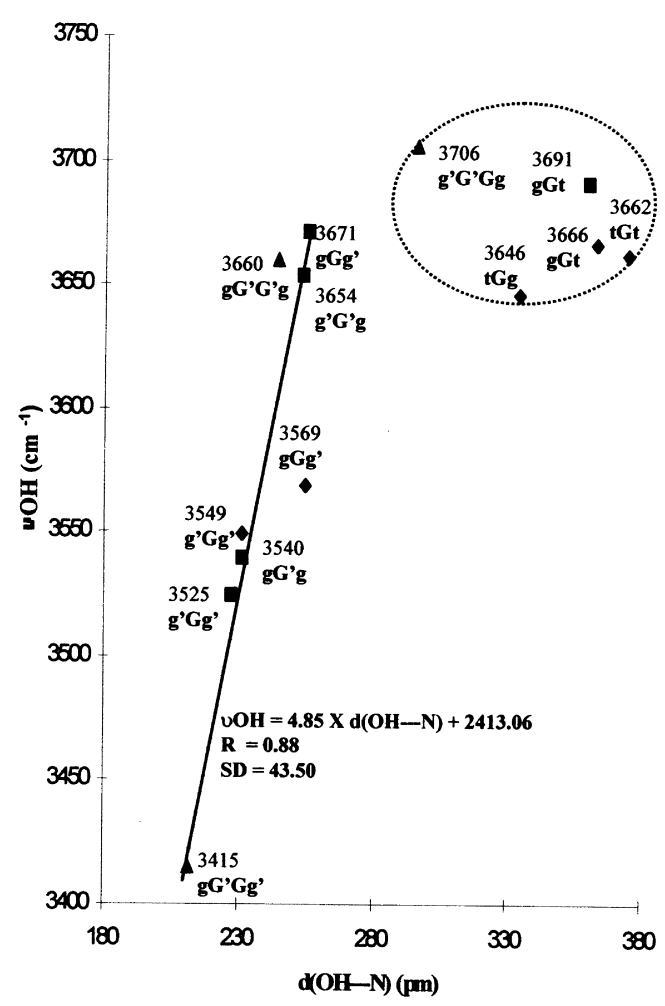

b)

Fig. 4. Plot of experimental frequencies ( $\nu \mathrm{OH}$, Ar matrix ir spectra) vs. calculated $\mathrm{d}(\mathrm{OH} \cdots \mathrm{N})$ distances for the most stable conformers of $\mathbf{2} \mathbf{A E}$ $(v)$, 2AP $(\nu)$ and 3AP $(\sigma)$ using: (a) MP2; and (b) HF calculated $\mathrm{d}(\mathrm{OH} \cdots \mathrm{N})$ distances.

frequency of the $\nu \mathrm{OH}$ mode (in argon) and the calculated $\mathrm{d}(\mathrm{OH} \cdots \mathrm{N})$ distance is shown for the most stable conformers of 2AE, 2AP and 3AP. These data includes results previously obtained for $\mathbf{2 A E}$ and 3AP $[3,4]$. Both HF and MP2 levels of theory predict a good linear correlation between the calculated $\mathrm{d}(\mathrm{OH} \cdots \mathrm{N})$ distance and the observed $\nu \mathrm{OH}$ stretching vibration for all conformers exhibiting an $\mathrm{OH} \cdots \mathrm{N}$ intramolecular hydrogen bond: the shorter the $\mathrm{d}(\mathrm{OH} \cdots \mathrm{N})$ distance - i.e. the stronger the hydrogen bonding - the lower the $\nu \mathrm{OH}$ stretching frequencies. In addition, $\nu \mathrm{OH}$ appears nearly at the same frequency in all those conformers that do not have the $\mathrm{OH}$ group participating in the $\mathrm{OH} \cdots \mathrm{N}$ intramolecular hydrogen-bonding interaction. It is interesting to note that a similar general correlation between the calculated $\mathrm{O}-\mathrm{H}$ bond lengths for the three aminoalcohols and $\nu \mathrm{OH}$ could not be found. Instead, in this case, three different straight lines are necessary to fit the experimental data, one for each compound (as it could be expected, all conformers belonging to a given molecule follow approximately these relationships, despite they have or not the hydroxyl group participating in hydrogen bonding). The absolute value of the slope of each individual $\nu \mathrm{OH}$ vs. $\mathrm{d}(\mathrm{O}-$ H) straight line increases in the order $\mathbf{2 A E}<\mathbf{2 A P}<\mathbf{3}$ AP. This result can be correlated with the progressive strengthening of the intramolecular $\mathrm{OH} \cdots \mathrm{N}$ hydrogen bond in these compounds, as it is also indicated by the relative values of the $\nu \mathrm{OH}$ frequencies for the most stable conformers, having the strongest $\mathrm{OH} \cdots \mathrm{N}$ hydrogen bond, of each molecule (3AP: $3415 \mathrm{~cm}^{-1}$; 2AP: $3525 \mathrm{~cm}^{-1}$; 2AE: $3549 \mathrm{~cm}^{-1}$ - see Table 9 and Refs. [3,4]).

The assignments of the $\nu \mathrm{OH}$ bands in the matrix isolated 2AP spectra are reinforced by the solution 


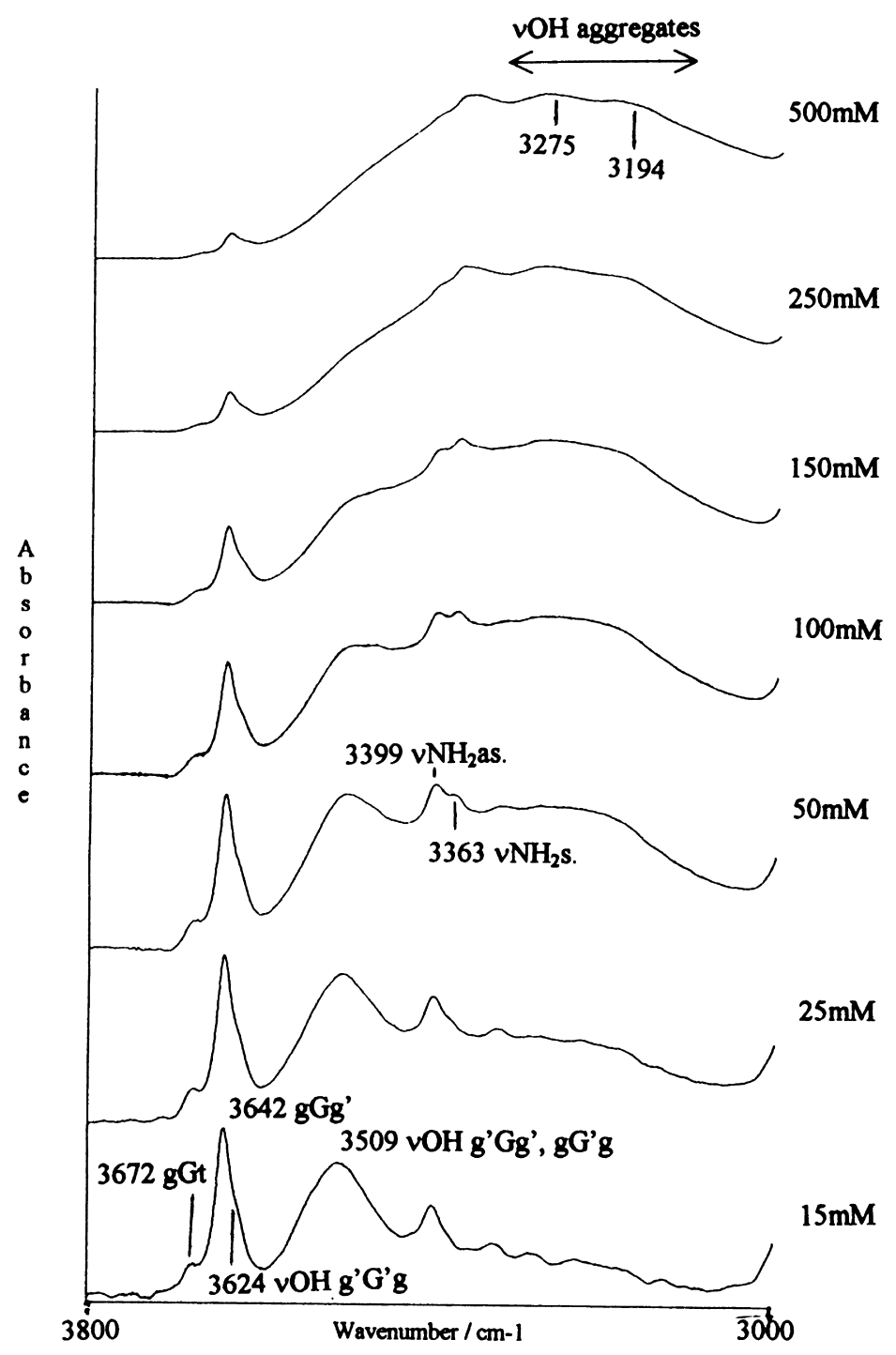

Fig. 5. Infrared $\mathrm{OH}$ stretching region of some $\mathrm{CCl}_{4}$ solutions of 2-amino-1-propanol.

studies in tetrachloromethane and trans-1,2-dichloroethylene, being qualitatively similar in both solvents. The data obtained in $\mathrm{CCl}_{4}$ solution are presented in Fig. 5, where $\nu \mathrm{OH}$ bands due to the different conformers and aggregated species are clearly indicated. For very low concentrations of $\mathbf{2 A P}$, besides the bands due to the $\mathrm{NH}_{2}$ symmetric and asymmetric stretching modes, appearing, respectively, at $3399 \mathrm{~cm}^{-1}$ and $3363 \mathrm{~cm}^{-1}$, the spectra show a relatively broad band centered at $3509 \mathrm{~cm}^{-1}$ due to the conformers $\mathbf{g}^{\prime} \mathbf{G} \mathbf{g}^{\prime}$ and $\mathbf{g G}^{\prime} \mathbf{g}$, which have a strong $\mathrm{OH} \cdots \mathrm{N}$ intramolecular hydrogen bond, and three narrower bands, at higher frequencies (3624, 3642 and $3672 \mathrm{~cm}^{-1}$ ), ascribable, respectively, to the two conformers which have a relatively weak $\mathrm{OH} \cdots \mathrm{N}$ intramolecular hydrogen bond $\left(\mathbf{g}^{\prime} \mathbf{G}^{\prime} \mathbf{g}\right.$ and $\left.\mathbf{g G g}{ }^{\prime}\right)$ and to conformer $\mathbf{g G t}$, where the $\mathrm{OH}$ group is not involved in the $\mathrm{OH} \cdots \mathrm{N}$ interaction. Note that all bands observed in the solution spectra are red shifted by ca. $20-30 \mathrm{~cm}^{-1}$ with respect to the correspondent bands observed in the matrices, a result that agrees with the relative polarity of the environment. Upon raising the concentration, the bands due to 
the different monomeric species strongly decrease their intensity, while a very broad band with maxima at 3275 and $3194 \mathrm{~cm}^{-1}$, ascribable to the $\nu \mathrm{OH}$ vibration of aggregated species containing an $\mathrm{OH} \cdots \mathrm{N}$ intermolecular hydrogen bond, start to dominate the spectra.

\subsection{2. $\mathrm{NH}_{2}$ wagging vibrations}

The two most intense infrared bands of 2AP predicted by the calculations correspond to the $\nu \mathrm{C}-$ $\mathrm{O}$ and $\omega \mathrm{NH}_{2}$ vibrations of the most stable conformer (see Table 9). Based on their intensities, these two modes can be unequivocally assigned to the doublet at 1065 and $1063 \mathrm{~cm}^{-1}$ and to the band at $794 \mathrm{~cm}^{-1}$, respectively (in argon). However, the calculations predict that the wagging vibration should occur at a higher frequency (calculated value: $875 \mathrm{~cm}^{-1}$ ), the relative error in the theoretical value being clearly larger for this mode than for all other vibrations. A similar situation happens for the $\omega \mathrm{NH}_{2}$ vibration of conformer $\mathbf{g G}^{\prime} \mathbf{g}$, which is also a conformer having a strong $\mathrm{OH} \cdots \mathrm{N}$ intramolecular hydrogen bond. On the contrary, the agreement between the calculated and experimental frequencies for this mode in the remaining observed conformers is much better, despite a general overestimation of the calculated frequencies can be noticed. (see Table 9). It is well known that ab initio calculations carried out at the level of theory used here cannot account for some subtle effects associated with hydrogen bonding $[14,23]$. So, the involvement of the nitrogen atom in the $\mathrm{OH} \cdots \mathrm{N}$ intramolecular hydrogen bond, where it acts exclusively as hydrogen bond acceptor, seems to contribute, at least in part, to red shift the frequency of the $\omega \mathrm{NH}_{2}$. A possible explanation for this is to consider that, when the amine group is involved in a strong $\mathrm{OH} \cdots \mathrm{N}$ intramolecular hydrogen bond, the nitrogen lone electron pair becomes more concentrated along the direction of this bond, and this electronic migration opens up more space for the wagging vibration of the amine hydrogen atoms to occur, thus reducing the force constant associated with this coordinate and, consequently, red shifting their frequency.

\subsubsection{Low frequency vibrations}

The spectral region below $400 \mathrm{~cm}^{-1}$ was not experimentally investigated in this study, but the calculations predicted frequencies of the vibrations, which should give, rise to bands in this region. As mentioned above, some of the low frequency modes of conformers $\mathbf{g}^{\prime} \mathbf{G g}^{\prime}$ and $\mathbf{g G}^{\prime} \mathbf{g}$ were reported by Ellingsen, Marstokk and Møllendal [12], who also proposed their assignments. The results of the $a b$ initio calculations presented now confirm the assignments made by those authors. Thus, for the conformational ground state, the frequencies of the $\tau \mathrm{OCCN}$ and $\tau \mathrm{CCCH}$ modes $\left(199 \pm 49\right.$ and $\left.126 \pm 10 \mathrm{~cm}^{-1}\right)$ obtained from the microwave spectra of 2AP [12], may be compared with the corresponding theoretical (scaled) frequencies: 225 and $150 \mathrm{~cm}^{-1}$. In addition, the third lowest frequency mode of this conformer, as proposed by Ellingsen et al. [12], corresponds to a bending mode ( $\delta \mathrm{CCC}-$ see Table 4$)$. For conformer $\mathbf{g G}^{\prime} \mathbf{g}$, the observed and calculated frequencies of the $\tau \mathrm{OCCN}$ and $\tau \mathrm{CCCH}$ modes are, respectively, $144 \pm$ 26 and $225 \pm 26 \mathrm{~cm}^{-1}$ [12], and 145 and $217 \mathrm{~cm}^{-1}$.

\subsection{Temperature variation infrared studies (annealing of the matrices)}

The results of Barnes [24,25] indicate that energy barrier heights higher than $10-12 \mathrm{~kJ} \mathrm{~mol}^{-1}$ are needed in order to avoid establishment of a conformational thermal equilibrium for a substance in a matrix annealed to ca. $30 \mathrm{~K}$. Thus, both argon and krypton matrices were annealed to about this temperature, in order to search for any substantial reorganization of relative band intensities. Within the range of temperatures covered, no evidence was found of conformer isomerization, indicating that energy barriers separating the different observed conformers are higher than $10-12 \mathrm{~kJ} \mathrm{~mol}^{-1}$, in agreement with previous data on 2AE [13]. On the contrary, bands due to aggregates can be observed in the spectra above $30 \mathrm{~K}$, the transformation of monomeric species to aggregates being caused by loosening of the lattice of the matrices. The aggregation was found to be more extensive in krypton than in argon, a result that seems to indicate that a more significant matrix reorganization is required to enable diffusion of the solute molecules in the case of the argon matrix (this, in turn, is possibly determined by the smaller size of the argon when compared with the krypton atoms; i.e. in order to enable effective diffusion of the molecules of the solute, a greater number of argon than krypton atoms must undertake positional changes). 

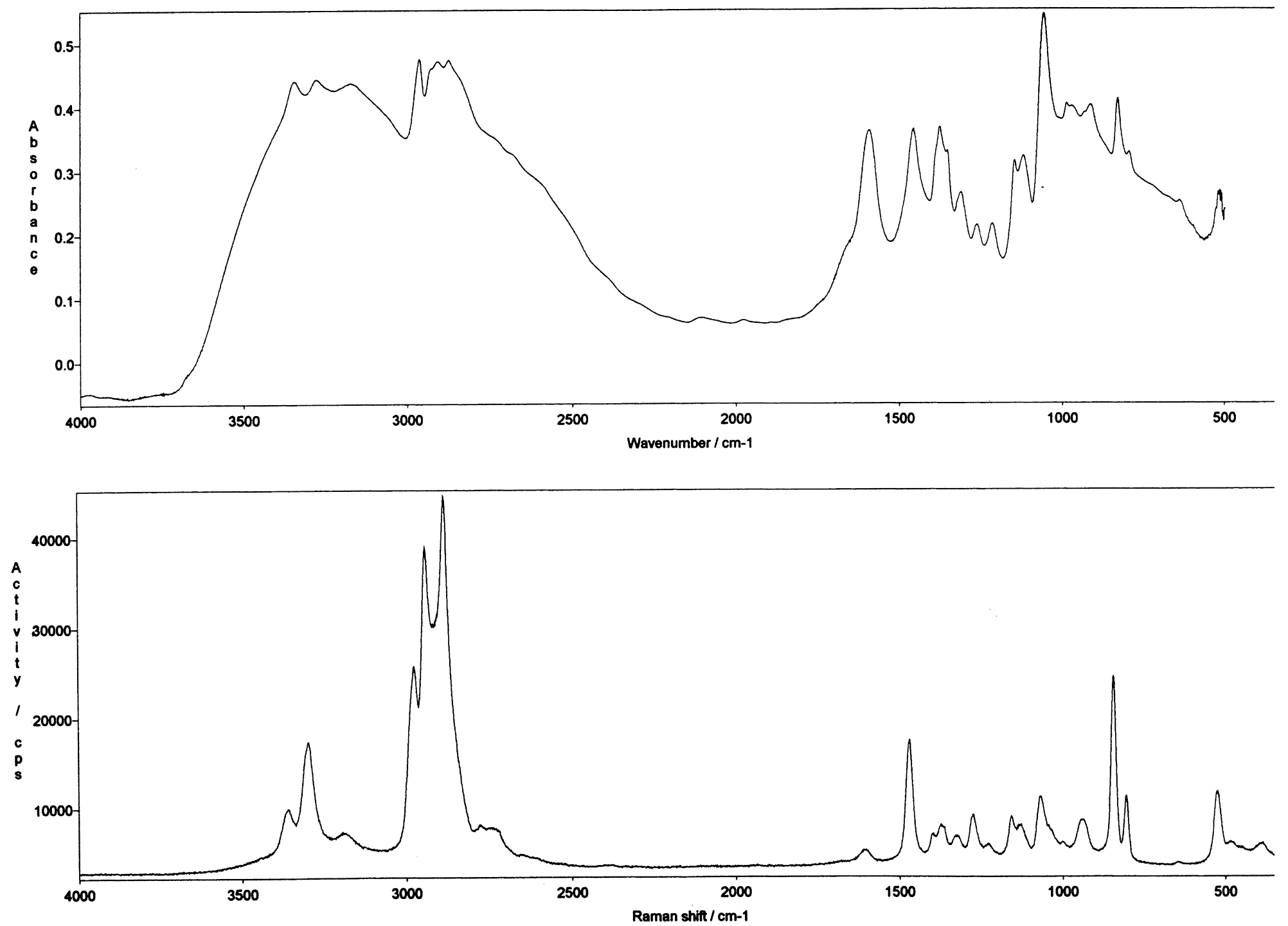

Fig. 6. Room temperature liquid phase infrared (upper) and Raman (bottom) spectra of 2-amino-1-propanol. 


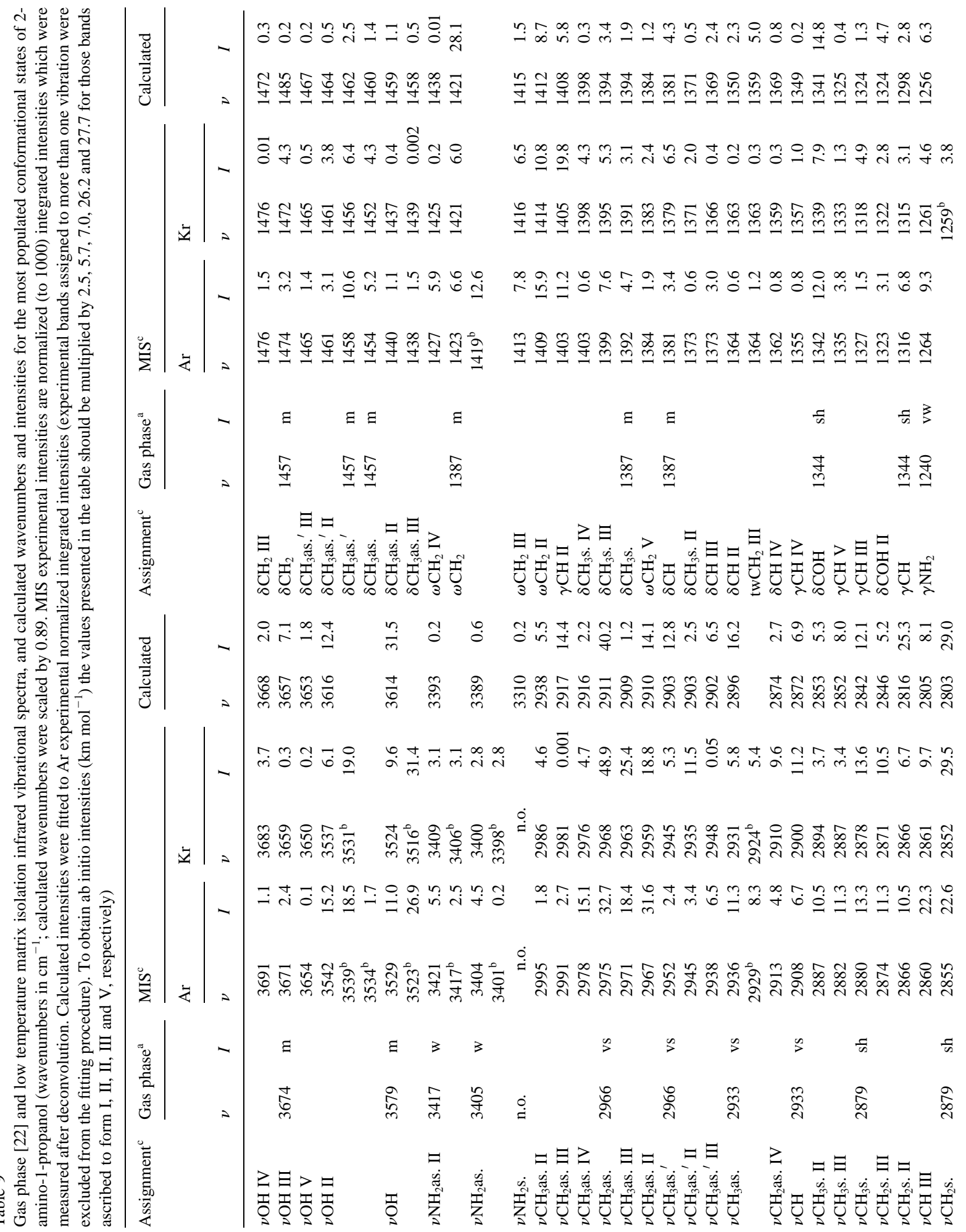




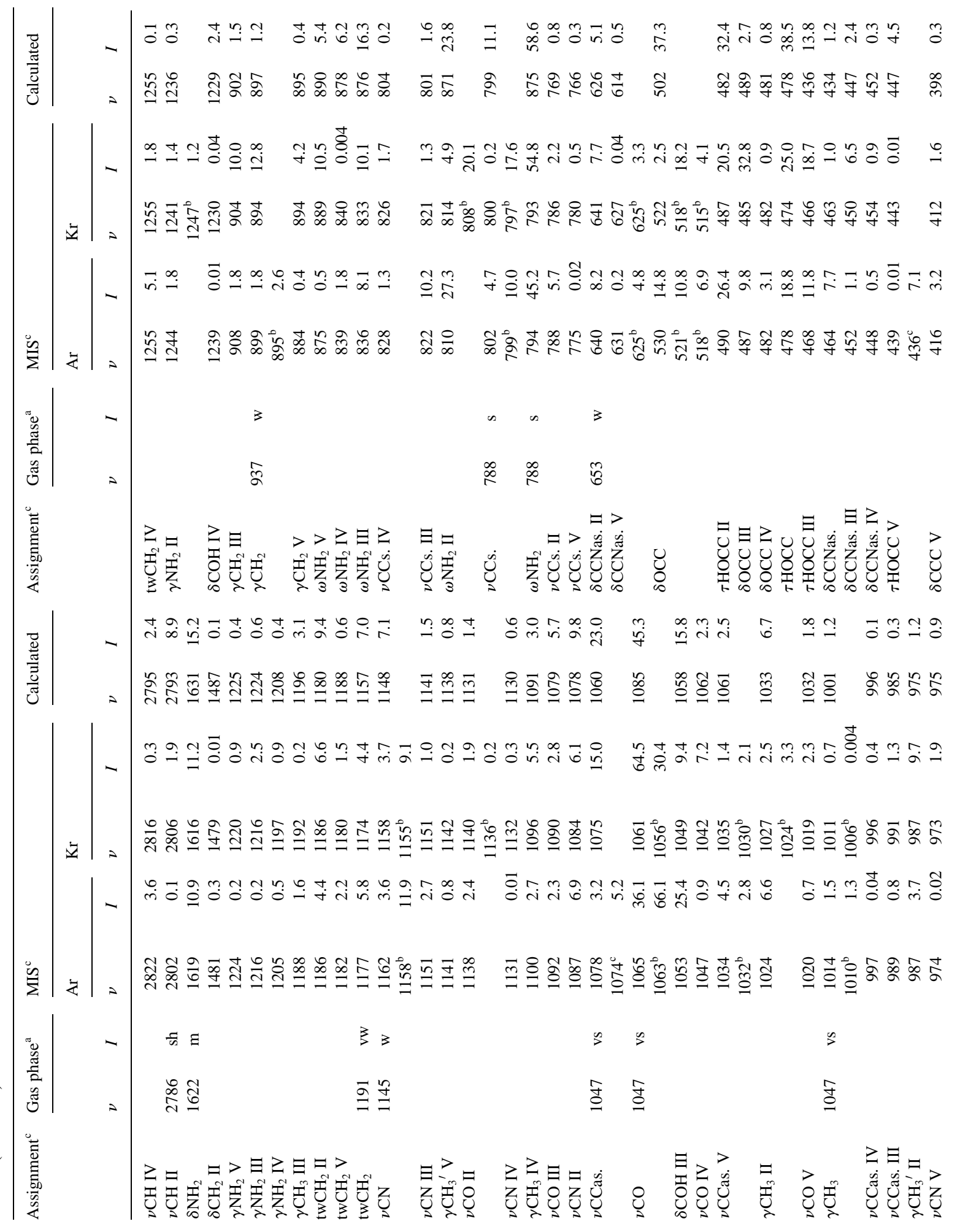




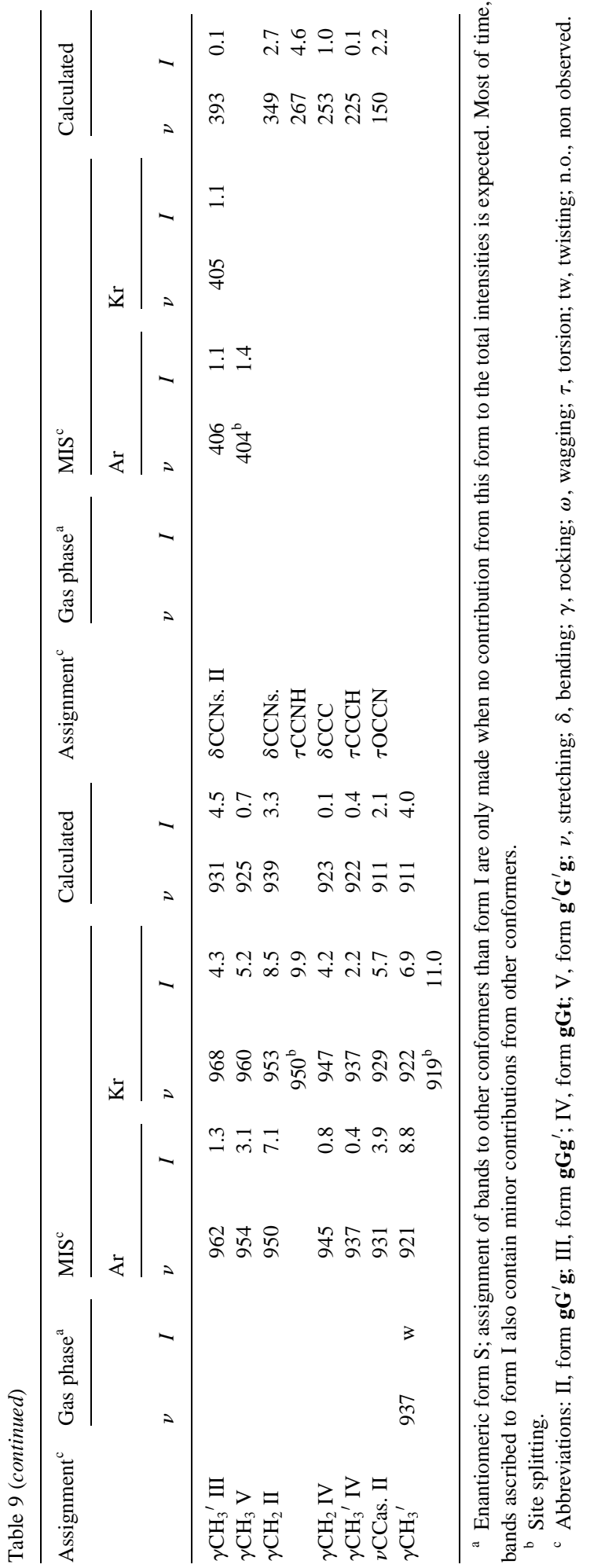

Table 10

Comparison of the infrared (ir) and Raman (R) spectra of pure liquid with the calculated spectra of form $\mathbf{g G t}$ (see text) (wavenumbers, $\nu$, in $\mathrm{cm}^{-1}$; calculated wavenumbers were scaled by 0.89 . Infrared experimental intensities $(I)$ presented as qualitative relative intensities; infrared ab initio intensities in $\mathrm{km} \mathrm{mol}^{-1}$. Raman experimental intensities are normalized (to 1000) integrated intensities which were measured after deconvolution; Raman calculated intensities were fitted to Raman experimental normalized integrated intensities (experimental bands assigned to more than one vibration were excluded from the fitting procedure). To obtain Raman ab initio intensities $\left(\mathrm{km} \mathrm{mol}^{-1}\right)$ the values presented in the table should be multiplied by 1.74)

\begin{tabular}{|c|c|c|c|c|c|c|c|}
\hline \multicolumn{2}{|c|}{ Infrared } & \multicolumn{2}{|c|}{ Raman } & \multicolumn{3}{|c|}{ Calculated } & \multirow[t]{2}{*}{ Assignment ${ }^{\mathrm{a}}$} \\
\hline$\nu$ & $I^{\mathrm{ir}}$ & $\nu$ & $I^{\mathrm{R}}$ & $\nu$ & $I^{\mathrm{ir}}$ & $I^{\mathrm{R}}$ & \\
\hline 3348 & vs & 3365 & 37.8 & 3399 & 3.3 & 37.0 & $\nu \mathrm{NH}_{2}$ as. \\
\hline 3282 & vs & 3301 & 80.3 & 3322 & 2.7 & 57.1 & $\nu \mathrm{NH}_{2} \mathrm{~s}$. \\
\hline 3174 & vs & 3191 & 27.1 & $3668^{b}$ & 53.2 & 61.9 & $\nu \mathrm{OH}$ \\
\hline 2963 & vs & 2977 & 35.6 & 2916 & 57.2 & 33.6 & $\nu \mathrm{CH}_{3}$ as. \\
\hline 2928 & vs & \multirow{3}{*}{2941} & \multirow{3}{*}{175.7} & $\{2902$ & 53.2 & 42.0 & $\nu \mathrm{CH}_{3}$ as. \\
\hline \multirow[t]{2}{*}{2906} & vs & & & 2874 & 70.9 & 18.3 & $\nu \mathrm{CH}_{2}$ as. \\
\hline & & & & 2851 & 41.0 & 86.9 & $\nu \mathrm{CH}_{3} \mathrm{~s}$. \\
\hline \multirow[t]{2}{*}{2874} & \multirow[t]{2}{*}{ vs } & \multirow[t]{2}{*}{2884} & 299.9 & 2836 & 49.4 & 27.5 & $\nu \mathrm{CH}_{2} \mathrm{~s}$ \\
\hline & & & & 2795 & 63.5 & 61.7 & $\nu \mathrm{CH}$ \\
\hline \multirow[t]{3}{*}{1595} & \multirow[t]{3}{*}{$\mathrm{s}$} & \multirow[t]{3}{*}{1606} & 20.4 & 1632 & 47.9 & 3.2 & $\delta \mathrm{NH}_{2}$ \\
\hline & & & & 1485 & 5.4 & 6.0 & $\delta \mathrm{CH}_{2}$ \\
\hline & & & & 1467 & 0.9 & 4.3 & $\delta \mathrm{CH}_{3}$ as. \\
\hline \multirow[t]{2}{*}{1459} & \multirow[t]{2}{*}{ s } & \multirow[t]{2}{*}{1469} & 43.8 & 1461 & 4.0 & 8.9 & $\delta \mathrm{CH}_{3}$ as. \\
\hline & & & & 1438 & 0.3 & 2.4 & $\omega \mathrm{CH}_{2}$ \\
\hline 1377 & $\mathrm{~s}$ & 1393 & 13.1 & 1398 & 7.1 & 0.9 & $\delta \mathrm{CH}_{3} \mathrm{~s}$. \\
\hline 1353 & $\mathrm{~m}$ & 1372 & 16.2 & 1369 & 21.6 & 5.1 & $\delta \mathrm{CH}$ \\
\hline 1312 & $\mathrm{~m}$ & 1324 & 8.4 & 1349 & 4.1 & 1.0 & $\gamma \mathrm{CH}$ \\
\hline \multirow[t]{2}{*}{1262} & \multirow[t]{2}{*}{$\mathrm{m}$} & 1273 & 19.5 & 1255 & 2.2 & 10.4 & $\mathrm{twCH} \mathrm{CH}_{2}$ \\
\hline & & 1229 & 9.8 & 1229 & 63.3 & 3.0 & $\delta \mathrm{COH}$ \\
\hline 1215 & $\mathrm{~m}$ & $\{1202$ & 3.8 & 1208 & 10.4 & 1.5 & $\gamma \mathrm{NH}_{2}$ \\
\hline 1147 & $\mathrm{~s}$ & C1158 & 14.8 & 1130 & 14.5 & 2.0 & $\nu \mathrm{CN}$ \\
\hline 1120 & $\mathrm{~s}$ & 1131 & 14.9 & 1091 & 78.3 & 2.0 & $\gamma \mathrm{CH}_{3}$ \\
\hline 1058 & vs & 1068 & 20.2 & 1062 & 61.5 & 4.6 & $\nu \mathrm{CO}$ \\
\hline 989 & $\mathrm{~m}$ & 1042 & 14.3 & 996 & 1.3 & 2.3 & $\nu$ CCas. \\
\hline 972 & sh & 1002 & 7.9 & 923 & 2.0 & 1.3 & $\gamma \mathrm{CH}_{2}$ \\
\hline 935 & sh & & & $\int 922$ & 9.4 & 3.1 & $\gamma \mathrm{CH}_{3}$ \\
\hline 915 & $\mathrm{~m}$ & 941 & 32. & $\{878$ & 162.3 & 2.0 & $\omega \mathrm{NH}_{2}$ \\
\hline 832 & $\mathrm{~s}$ & 845 & 51.5 & 804 & 5.5 & 6.0 & $\nu$ CCs. \\
\hline \multirow[t]{8}{*}{520} & \multirow[t]{8}{*}{$\mathrm{m}$} & 527 & & 240 & 136.6 & 1.6 & $\tau \mathrm{HOCC}$ \\
\hline & & 485 & 7.8 & 481 & 19.8 & 1.2 & $\delta \mathrm{OCC}$ \\
\hline & & 455 & 7.1 & 452 & 7.4 & 0.5 & $\delta \mathrm{CCNas}$ \\
\hline & & 391 & 8.7 & $\{356$ & 6.4 & 0.3 & $\delta \mathrm{CCNs}$ \\
\hline & & & 0.1 & 305 & 43.4 & 1.3 & $\tau \mathrm{CCNH}$ \\
\hline & & 292 & 6.0 & $251^{\mathrm{b}}$ & 27.8 & 0.01 & $\gamma \mathrm{CCC}$ \\
\hline & & & & 222 & 0.5 & 0.03 & $\tau \mathrm{CCCH}$ \\
\hline & & & & 145 & 3.6 & 0.02 & $\tau \mathrm{OCCN}$ \\
\hline
\end{tabular}

a Abbreviations: $\nu$, stretching; $\delta$, bending; $\gamma$, rocking; $\omega$, wagging; $\tau$, torsion; tw, twisting.

$\mathrm{b}$ As it is usually observed [25], when the $\mathrm{OH}$ group participates in $\mathrm{H}$-bonding, the wavenumber of $\nu \mathrm{OH}$ decrease while that of $\tau \mathrm{HOCC}$ increase relatively to the isolated molecule situation. 
As expected, the frequencies of the most intense bands of the aggregated species - ascribable to $\nu \mathrm{OH}, \nu \mathrm{C}-\mathrm{O}, \omega \mathrm{NH}_{2}$ and $\tau \mathrm{HOCC}-$ were found to be shifted relatively to the monomeric species by ca. $-400,-10,100$ and $80 \mathrm{~cm}^{-1}$, i.e. $\nu \mathrm{OH}$ and $\nu \mathrm{C}-\mathrm{O}$ are red shifted in the aggregates whereas $\omega \mathrm{NH}_{2}$ and $\tau \mathrm{HOCC}$ increase their frequency in these species [26].

\subsection{Liquid phase infrared and Raman spectra}

Fig. 6 shows the infrared and Raman spectra of liquid 2AP. The proposed assignments are presented in Table 10.

Most of the bands of the spectra of the aggregates can be fairly well assigned taking as reference the calculated spectra of the monomeric form gGt, which shows that this is the preferred conformation assumed by the monomeric units within the aggregates. The intramolecular $\mathrm{NH} \cdots \mathrm{O}$ hydrogen bond exhibited by this conformer (the lowest energy form with an intramolecular $\mathrm{NH} \cdots \mathrm{O}$ hydrogen bond in isolated 2AP) makes the hydroxyl group more acidic and the amino group more basic, and then activates both $\mathrm{OH}$ and $\mathrm{NH}_{2}$ groups in order to establish the $\mathrm{OH} . \mathrm{N}$ intermolecular hydrogen bonding, the dominant intermolecular interaction present in the aggregated species. The importance of this intermolecular hydrogen bonding in liquid 2AP is also reflected in the frequencies of the bands assigned to $\nu \mathrm{O}-\mathrm{H}$, which strongly decreases when compared with those of the free monomeric species, and to $\tau \mathrm{HOCC}$, which increases when the $\mathrm{OH}$ group is involved in the intermolecular H-bonding [26] (see also Tables 9 and 10). These results are in agreement with the conclusions of our previous studies on $\mathbf{2 A \mathbf { E }}$ and $\mathbf{3 A P}$, where conformations structurally similar to form gGt of 2AP were also found to be the preferred configurations assumed by the monomeric units within the aggregates, in the liquid phase $[3,4]$.

As for $2 \mathbf{A E}$ [3], and contrarily to what was found for 3AP [4], temperature variation studies carried out on the pure liquid show that there are no detectable amounts of free monomeric molecules in the pure liquid 2AP. As mentioned in Section 1, the presence of the extra methyl group is expected to increase the basicity of the amino group and, consequently, the $\mathrm{O}-$
$\mathrm{H} \cdots \mathrm{N}$ hydrogen bonding in $\mathbf{2 A P}$ could be anticipated to be stronger than in $\mathbf{2 A E}$. This tendency was clearly confirmed in this study, whether by looking at the structural or the spectroscopic results (e.g. $\mathrm{d}(\mathrm{OH} \cdots \mathrm{N})$ distances and $\nu \mathrm{OH})$. However, the strength of this interaction in 2AP was found to be weaker than in $\mathbf{3 A P}$, and the liquid state results discussed now clearly show that it is not strong enough to enable free monomeric forms of $\mathbf{2 A P}$ to be present in significant quantities in this phase. This different behavior of $\mathbf{2 A P}$ and $\mathbf{3 A P}$ can be correlated with the increased conformational flexibility in 3AP that leads to a more favorable interaction geometry for the establishment of a sufficiently stronger intramolecular $\mathrm{OH} \cdots \mathrm{N}$ hydrogen bond that can be partially preserved in the liquid phase. These results also agree with a previous theoretical work on aminoalcohols, carried out using the 4-31G basis set, and indicating that the strength of the intramolecular $\mathrm{OH} \cdots \mathrm{N}$ interaction in linear aminoalcohols should increase with ring size [27].

Further, there is spectroscopic evidence that a minor amount, but still spectroscopically detectable quantity, of monomeric units assumes within the aggregates a completely different conformation. This gives rise, for instance, to the low intensity infrared bands at 797 and $641 \mathrm{~cm}^{-1}$ (with corresponding Raman bands at 807 and $649 \mathrm{~cm}^{-1}$ ). These frequencies are similar to those of the $\nu \mathrm{C}-$ $\mathrm{C}$ and $\delta \mathrm{CCN}$ vibrations of the conformers having a gauche $\mathrm{C}-\mathrm{C}-\mathrm{C}-\mathrm{O}$ axis (e.g. $\mathbf{g G}^{\prime} \mathbf{g}$ : 778 and $640 \mathrm{~cm}^{-1}$, and $\mathbf{g}^{\prime} \mathbf{G}^{\prime} \mathbf{g}$ : 775 and $631 \mathrm{~cm}^{-1}$; see Fig. 1 and Table 9), while in the conformers where this axis is trans, these two modes give rise to bands that occur, respectively, at higher $\left(800-830 \mathrm{~cm}^{-1}\right.$; see Table 9) and lower (ca. $450 \mathrm{~cm}^{-1}$ ) frequencies. Thus, the results seem to indicate that the second most stable conformation assumed by the monomeric units within the aggregates in the liquid phase is in all possibility one having a gauche $\mathrm{C}-\mathrm{C}-\mathrm{C}-\mathrm{O}$ axis. Though the following assignment should still be seen as tentative, we propose that, since such structure should have its hydroxyl group participating in a intermolecular hydrogen bonding (what excludes forms $\mathbf{g G} \mathbf{g}^{\prime} \mathbf{g}$ and $\mathbf{g}^{\prime} \mathbf{G g}^{\prime}$ ), and considering the relative structures of the different conformers presented in Table 1, the best candidate is a structure close to form $\mathbf{g}^{\prime} \mathbf{G}^{\prime} \mathbf{t}$. 


\section{Acknowledgements}

The authors wish to thank Dr João Cecílio for his technical help. This work was funded by the PRAXIS XXI (QUI/2/2.1/412/94) research programme, also partially funded by FEDER. C. Cacela acknowledges a PhD grant (GGPXXI/BD/3873/96) from Fundação para a Ciência e Tecnologia, Lisbon.

\section{References}

[1] R.L. Sutton, Chem. Britain (1991) 432.

[2] The Biophysics of organ Cryopreservation, in: D.E. Pegg, A.M. Karow Jr. (Eds.), Plenum Press, New York, 1987.

[3] C.F.C.P. Silva, M.L.T.S. Duarte, R. Fausto, J. Mol. Struct. 482/483 (1999) 591.

[4] C. Cacela, M.L. Duarte, R. Fausto, Spectrochim. Acta (2000) (in press).

[5] Microcal origin (Version 4.0), copyright $^{\circledR}$, 1991-1995 Microcal software, Inc..

[6] K.K. Irikura, SYNSPEC, Physical and Chemical Properties Division, National Institute of Standards and Technology, Gaithersburg, MD 20899, USA, 1995.

[7] W.J. Hehre, R. Ditchefield, J.A. Pople, J. Chem. Phys. 56 (1972) 2257.

[8] M.J. Frisch, G.W. Trucks, H.B. Schelegel, P.M.W. Gill, B.G. Johson, M.W. Wong, J.B. Foresman, M.A. Robb, M. HeadGordon, E.S. Replogle, R. Gomperts, J.L. Andres, K. Raghavachari, J.S. Binkley, C. Gonzalez, R.L. Martin, D.J. Defrees, J. Baker, J.J.P. Stewart, J.A. Pople, Gaussian92/DFT (Revision G.2), Gaussian Inc., Pittsburgh, PA, 1993.

[9] H.B. Schlegel, PhD thesis, Queen's University, Kingston, Ontario, Canada, 1975.

[10] D.J. Defrees, A.D. McLean, J. Chem. Phys. 82 (1985) 333.
[11] M.D.G. Faria, R.Fausto, Transformer, Build-G and Vibrat (version 1.0), Departamento de Química, Universidade de Coimbra, Portugal, 1990.

[12] B.H. Ellingsen, K.-M. Marstoll, H. Møllendal, J. Mol. Struct. 48 (1978) 9.

[13] M. Räsänen, A. Aspiala, L. Homanen, J. Murto, J. Mol. Struct. 96 (1982) 81

[14] A. Kulbida, M.N. Ramos, M. Rasanen, J. Nieminen, O. Schrems, R. Fausto, J. Chem. Soc. Faraday Trans. 91 (1995) 1571.

[15] S.G. Stepanian, I.D. Reva, E.D. Radchenko, M.T.S. Rosado, M.L.T.S. Duarte, R. Fausto, L. Adamowicz, J. Phys. Chem. A 102 (1998) 1041.

[16] R. Ditchfield, K. Seidman, Chem. Phys. Lett. 54 (1978) 57.

[17] D.J. Defrees, B.A. Levi, S.K. Pollack, W.J. Hehre, J.S. Binkley, J.A. Pople, J. Am. Chem. Soc. 101 (1979) 4085.

[18] F.P.S.C. Gil, R. Fausto, A.M. Amorim da Costa, J.J.C. Teixeira-Dias, J. Chem. Soc. Faraday Trans. 90 (1994) 689.

[19] S.J. Lee, B.J. Mhin, S.J. Cho, J.Y. Lee, K.S. Kim, J. Phys. Chem. 98 (1994) 1129.

[20] L.A.E. Batista de Carvalho, J.J.C. Teixeira-Dias, R. Fausto, Struct. Chem. 1 (1990) 533.

[21] J.J.C. Teixeira-Dias, R. Fausto, J. Mol. Struct. 144 (1986) 199.

[22] EPA Vapor Phase Library (CAS 156-87-6), Galactic Industries Corp., 395 Main ST. Salem, NH 03079, USA, 1994.

[23] M.T. Rosado, M.L.T.S. Duarte, R. Fausto, Phosph. Sulf. Silic. 116 (1996) 153.

[24] A.J. Barnes, in: A.J. Barnes, W.J. Orville-Thomas, A. Müller, R. Gaufrès (Eds.), Matrix Isolation Spectroscopy, Reidel, Dordrecht, 1981, p. 531.

[25] A.J. Barnes, G.C. White, Proceedings of the 12th European Congress on Molecular Spectroscopy, Elsevier, Amsterdam, 1976, p. 373.

[26] R. Fausto, J. Mol. Struct. 377 (1996) 181.

[27] A.-M. Kelterer, M. Flock, M. Ramek, J. Mol. Struct. (Theochem.) 276 (1992) 61. 